\title{
Direct-type Catalytic Three-Component Mannich Reactions Leading to an Efficient Synthesis of $\alpha, \beta$-Diamino Acid Derivatives
}

\author{
Matthew M. Salter, Jun Kobayashi, Yusuke Shimizu, and Shu Kobayashi* \\ Graduate School of Pharmaceutical Sciences, The University of Tokyo, \\ The HFRE Division, ERATO, Japan Science and Technology Corporation (JST) \\ Hongo, Bunkyo-ku, Tokyo 113-0033, Japan
}

${ }^{1} \mathrm{H}$ and ${ }^{13} \mathrm{C}$ NMR spectra for compounds 2a-q, 5 
${ }^{1} \mathrm{H}$ NMR spectrum of compound $\mathbf{2 a}$
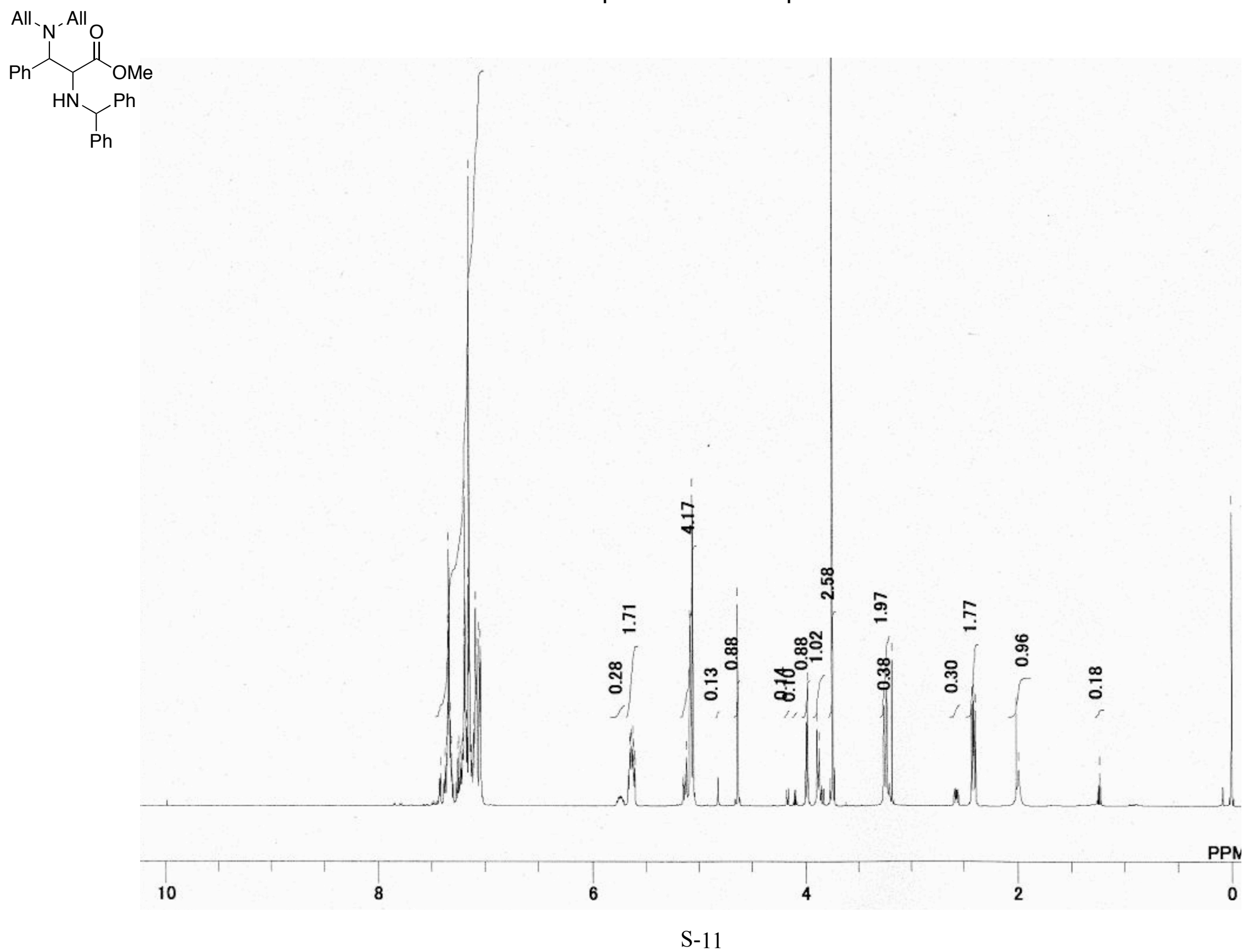
${ }^{13} \mathrm{C}$ NMR spectrum of compound $\mathbf{2 a}$

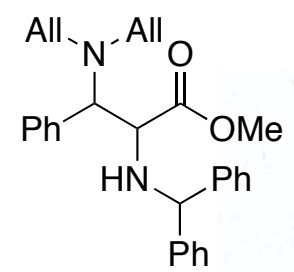$$
\mathrm{Ph}
$$

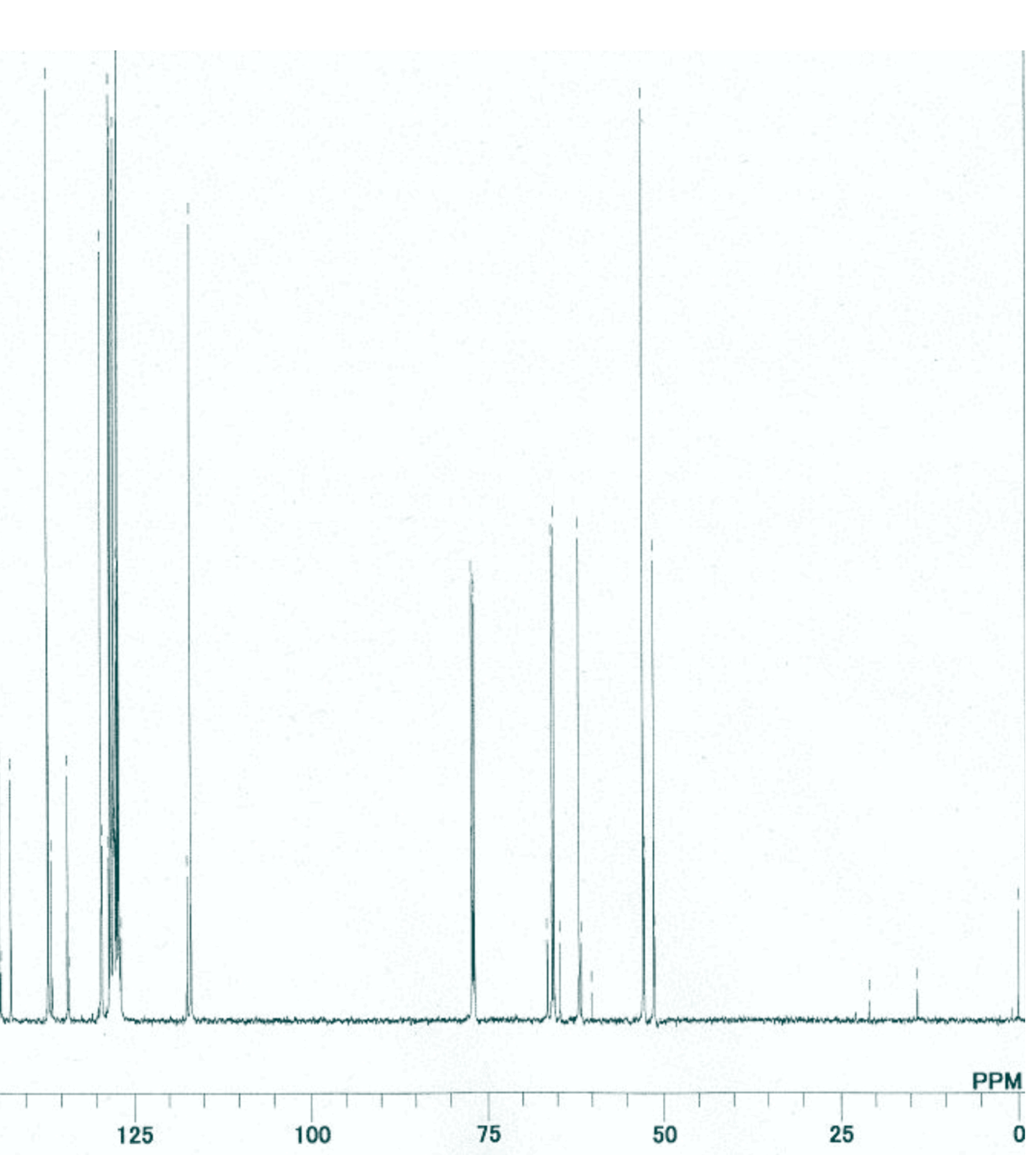

S-12 


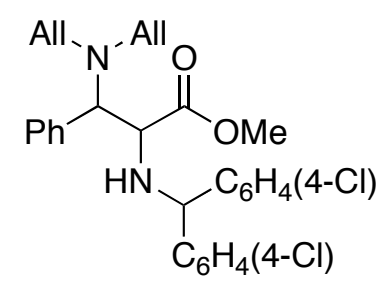

\section{${ }^{1} \mathrm{H}$ NMR spectrum of compound $\mathbf{2 b}$}

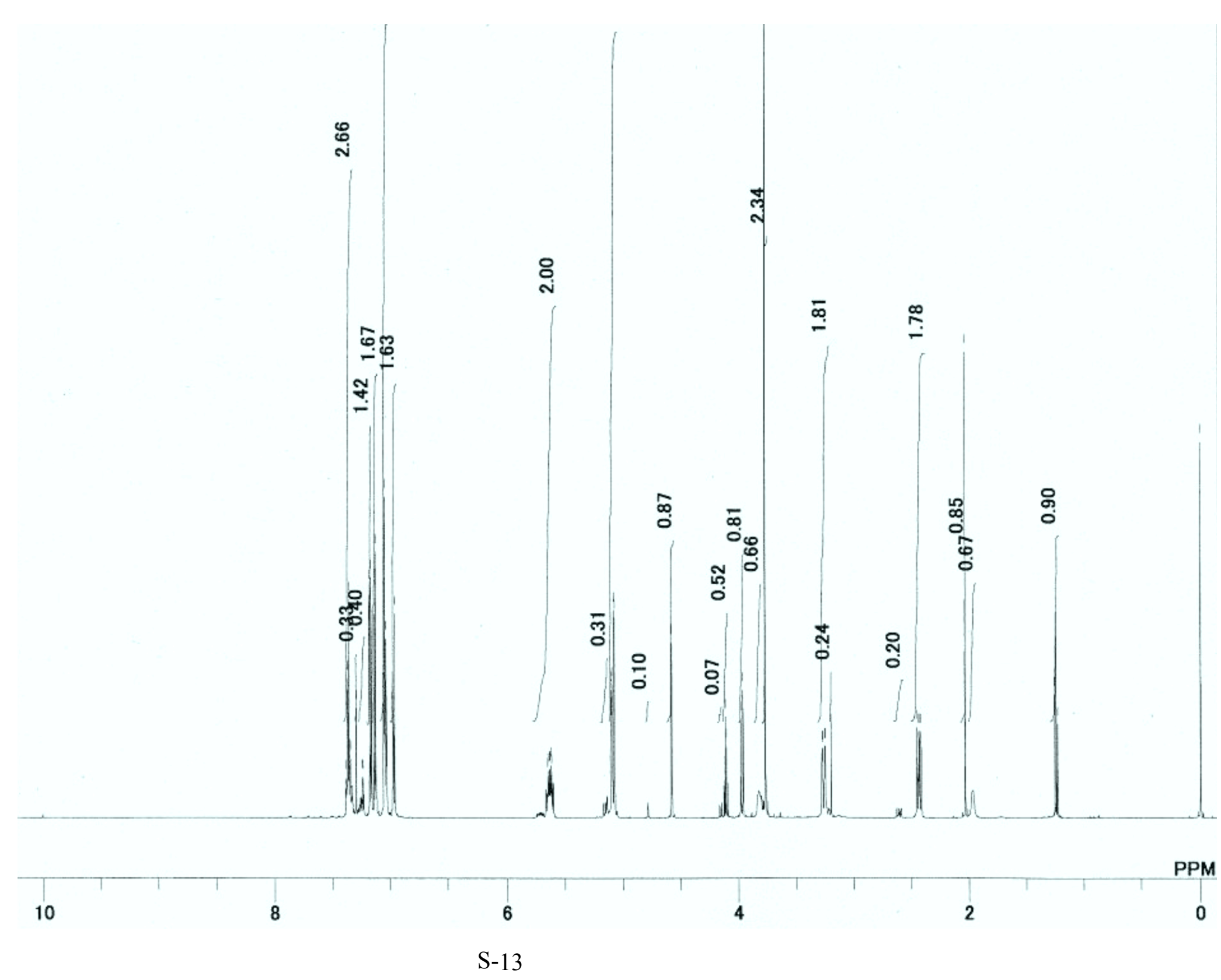


${ }^{13} \mathrm{C}$ NMR spectrum of compound $\mathbf{2 b}$
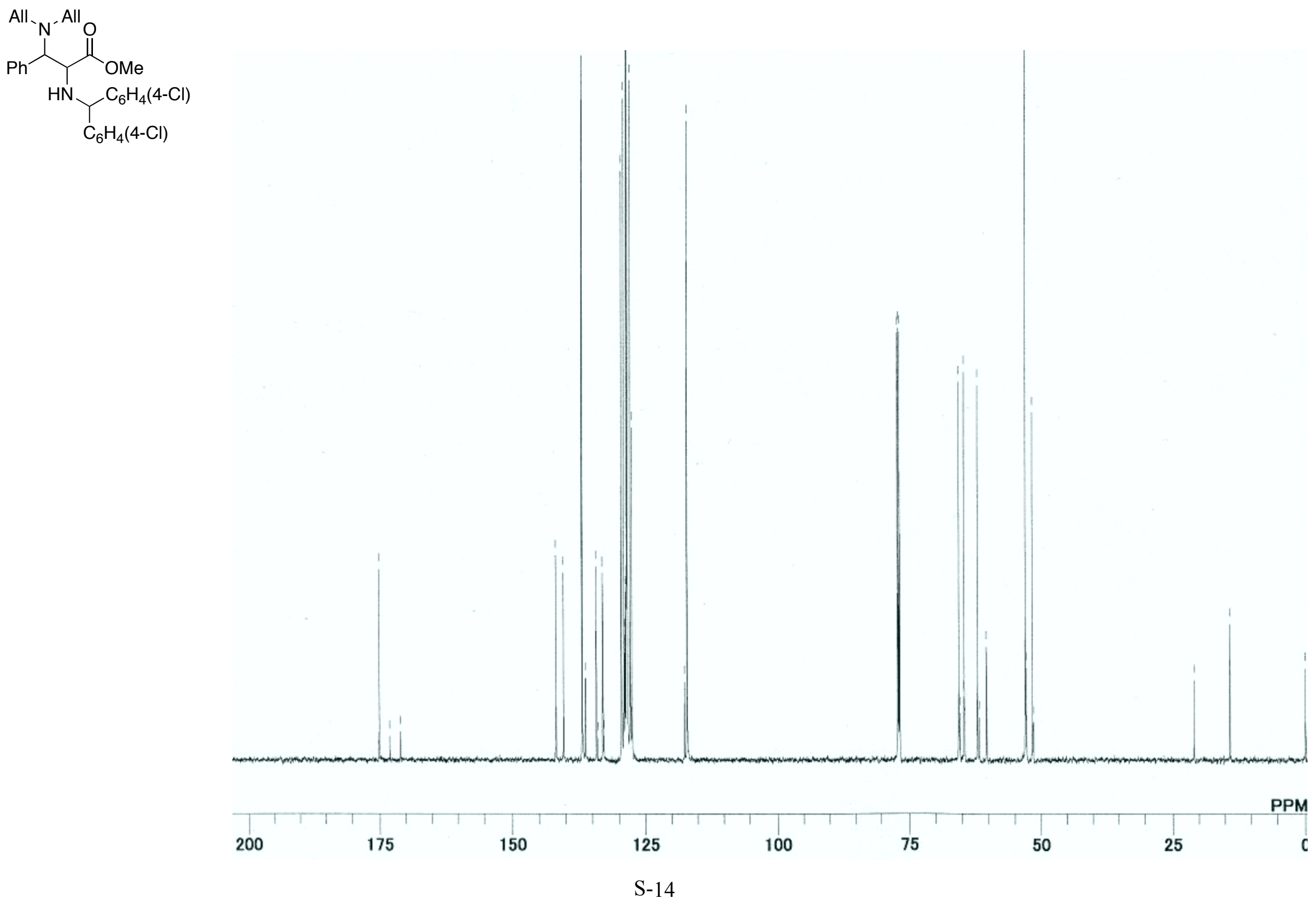
${ }^{1} \mathrm{H}$ NMR of compound 2c

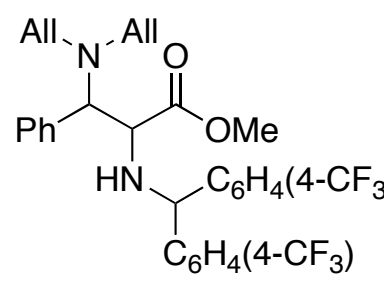

$\mathrm{C}_{6} \mathrm{H}_{4}\left(4-\mathrm{CF}_{3}\right)$
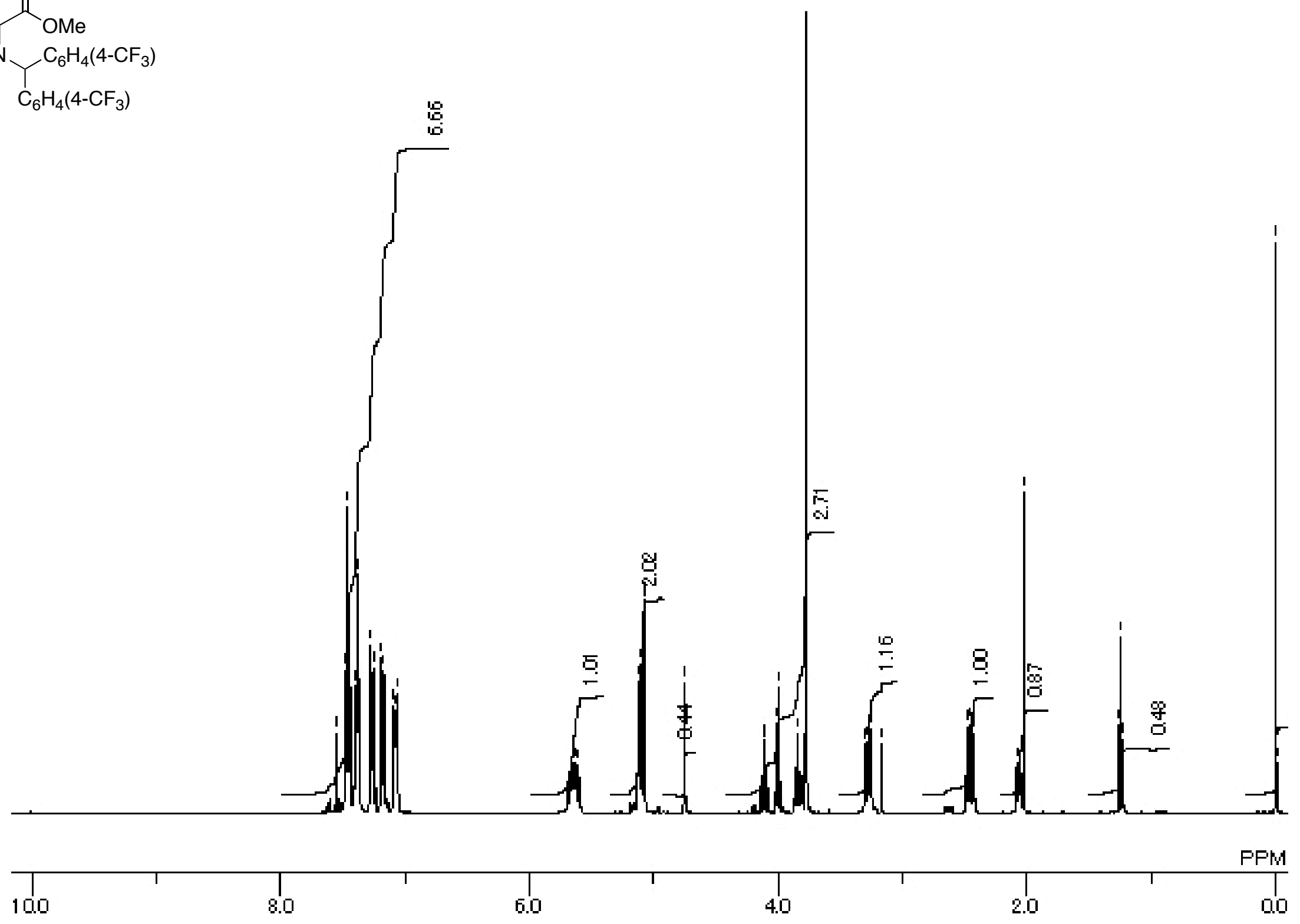

PPM 
${ }^{13} \mathrm{C}$ NMR of compound ac

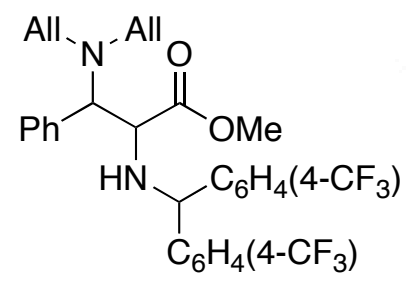
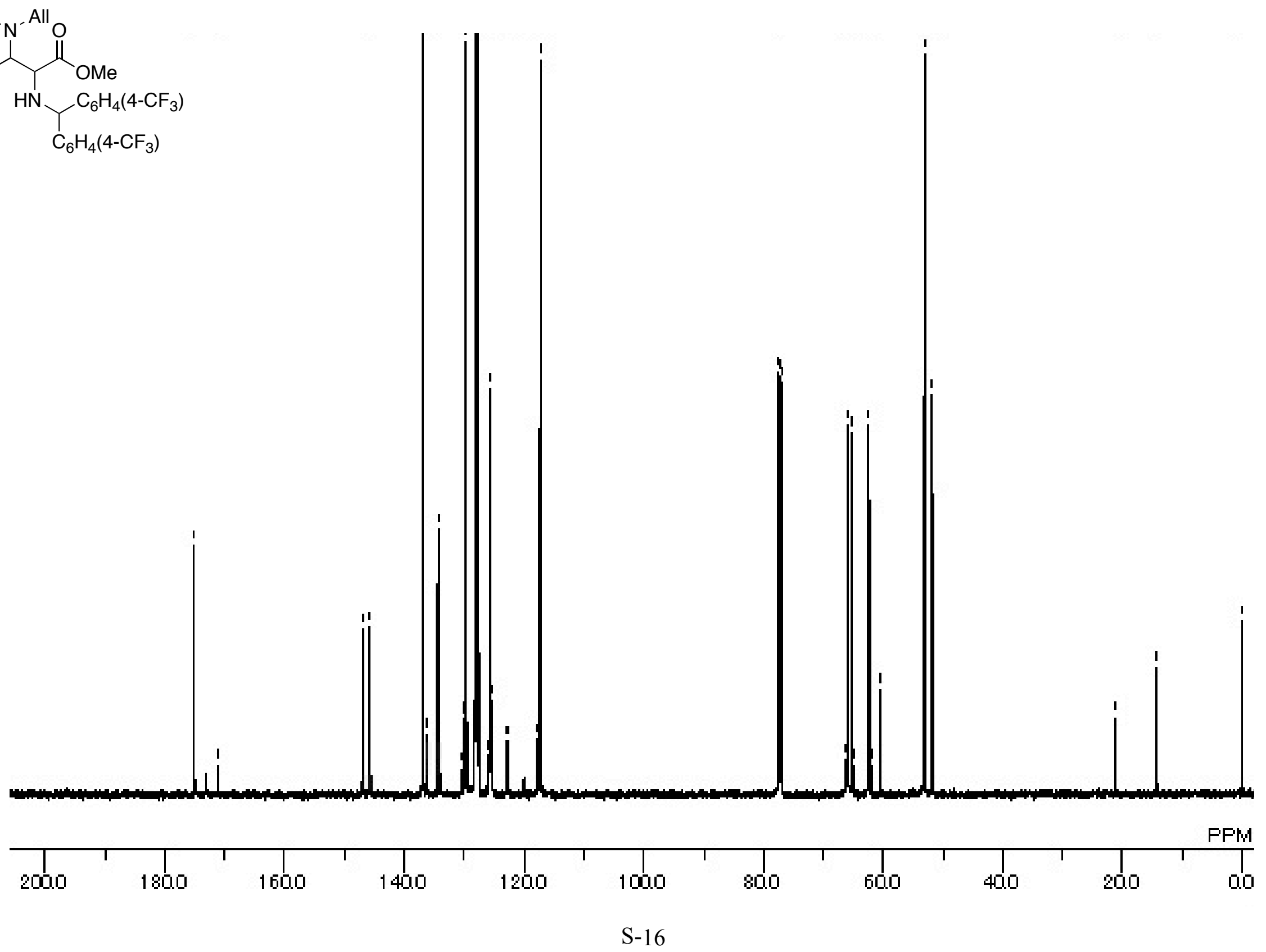
${ }^{1} \mathrm{H}$ NMR spectrum of compound $\mathbf{2 d}$
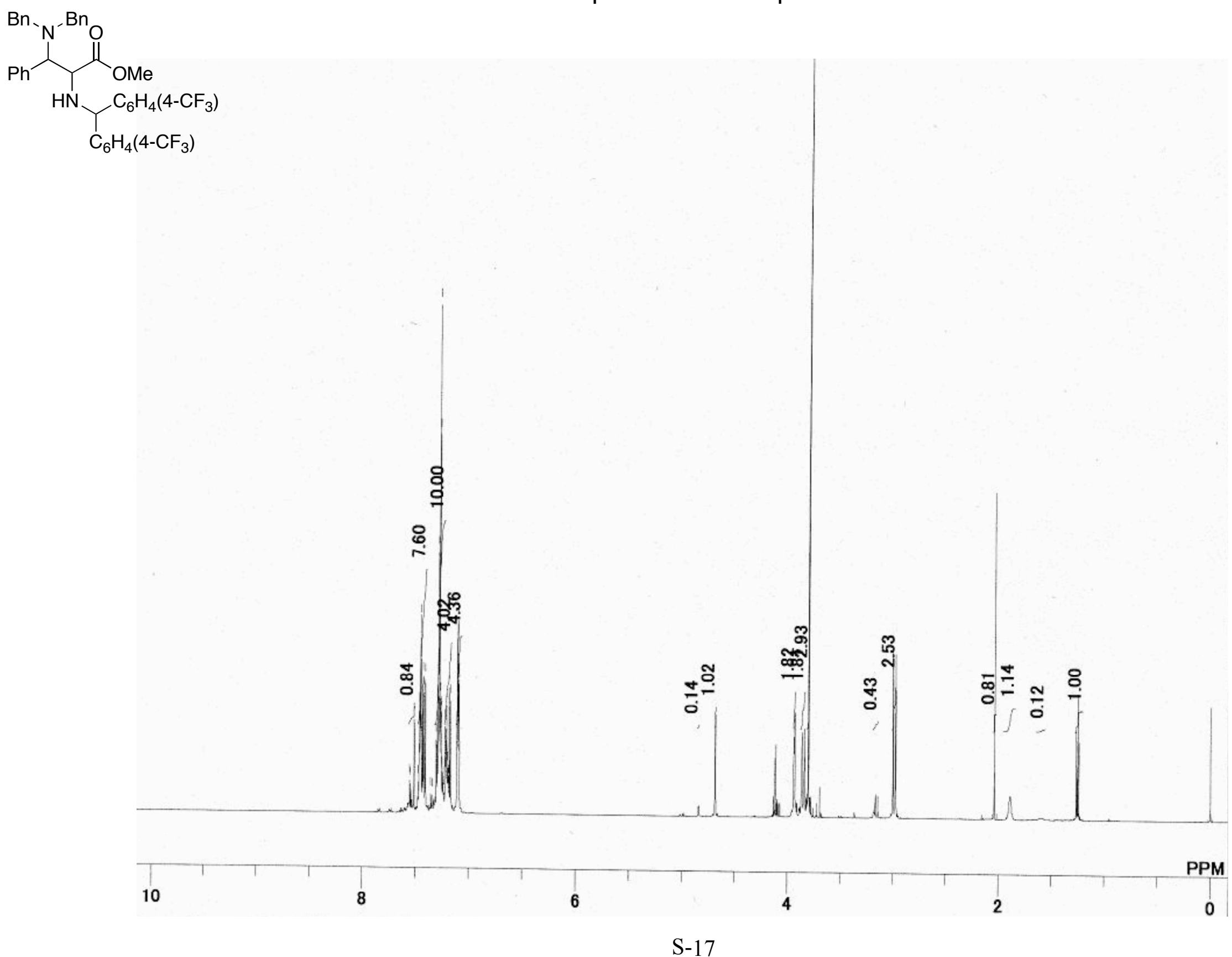
${ }^{13} \mathrm{C}$ NMR spectrum of compound $\mathbf{2 d}$

$$
\text { (N) }
$$




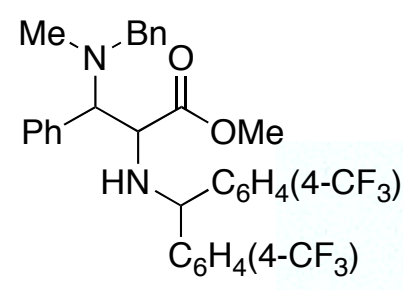

${ }^{1} \mathrm{H}$ NMR spectrum of compound $\mathbf{2 e}$

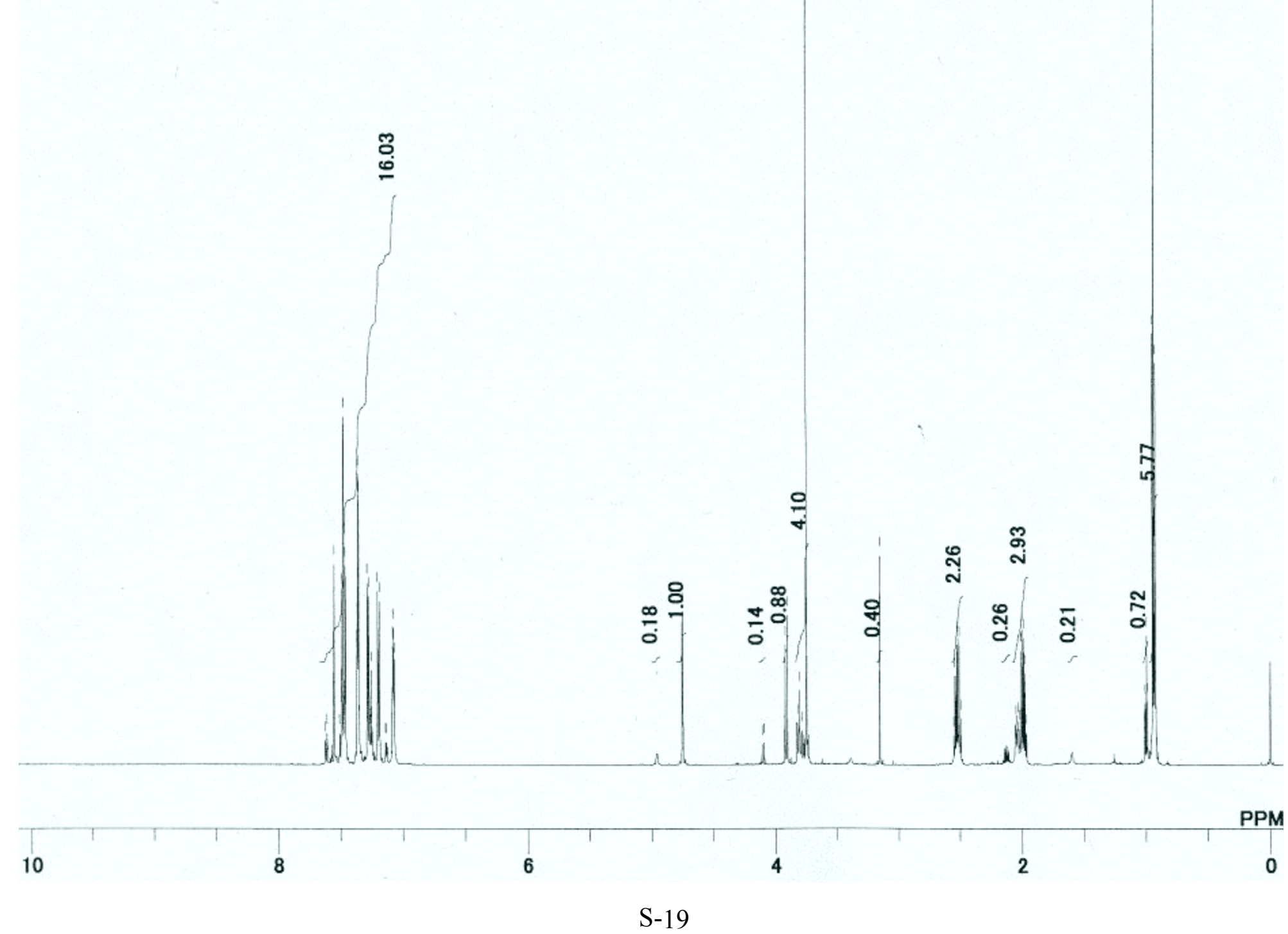


${ }^{13} \mathrm{C}$ NMR spectrum of compound $\mathbf{2 e}$

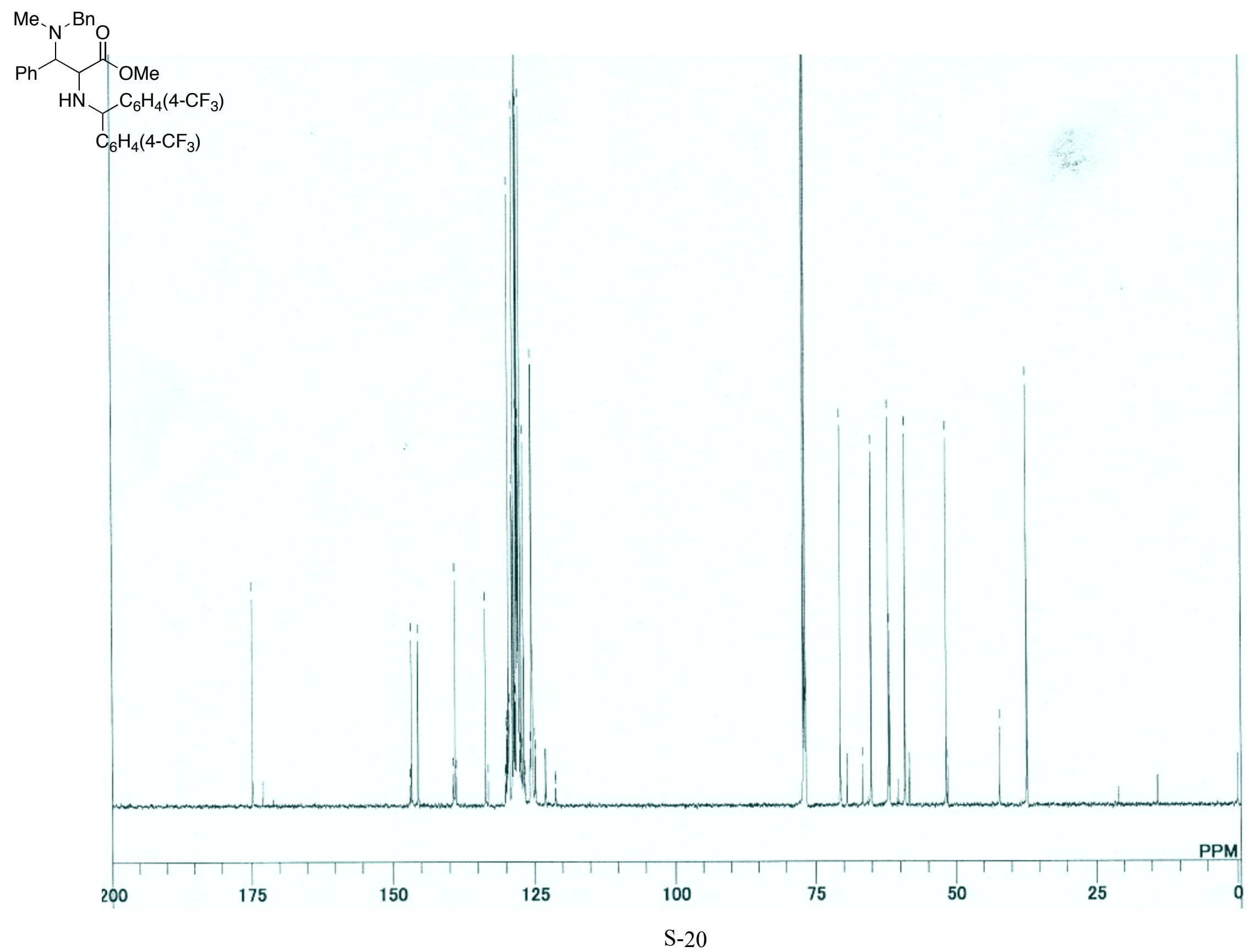


${ }^{1} \mathrm{H}$ NMR spectrum of compound $\mathbf{2 f}$
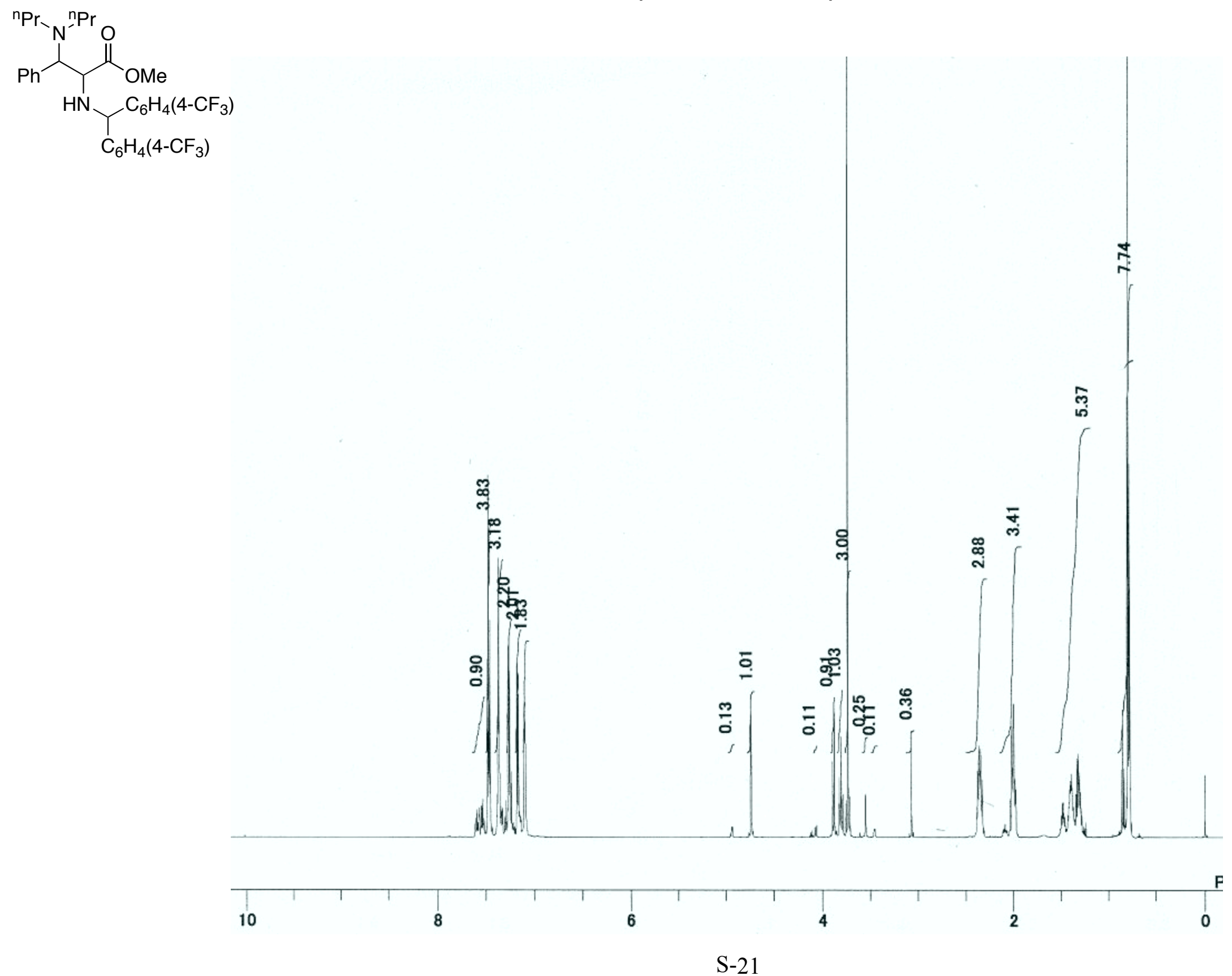
${ }^{13} \mathrm{C}$ NMR spectrum of compound $\mathbf{2 f}$

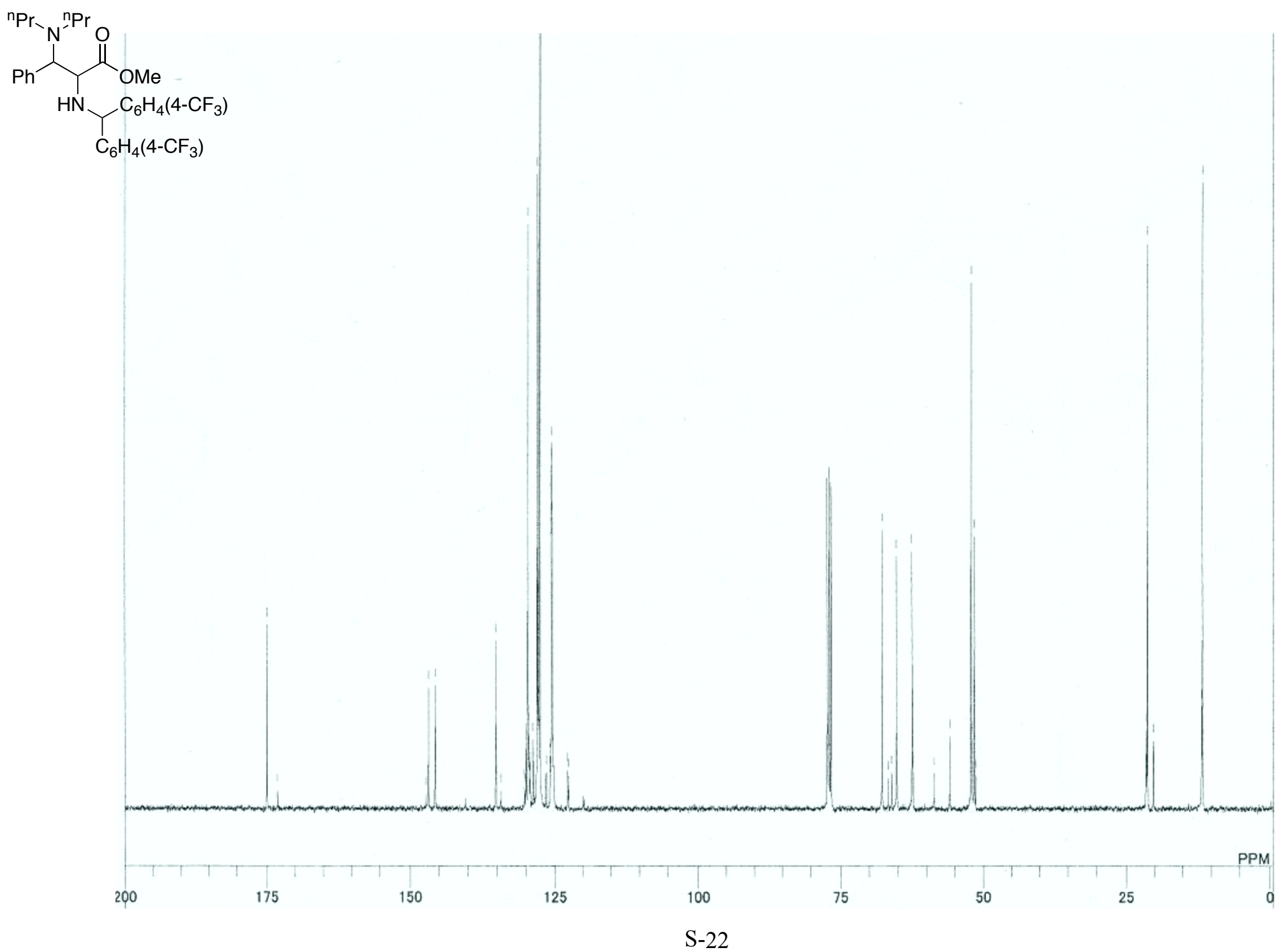


${ }^{1} \mathrm{H}$ NMR spectrum of compound $\mathbf{2 g}$
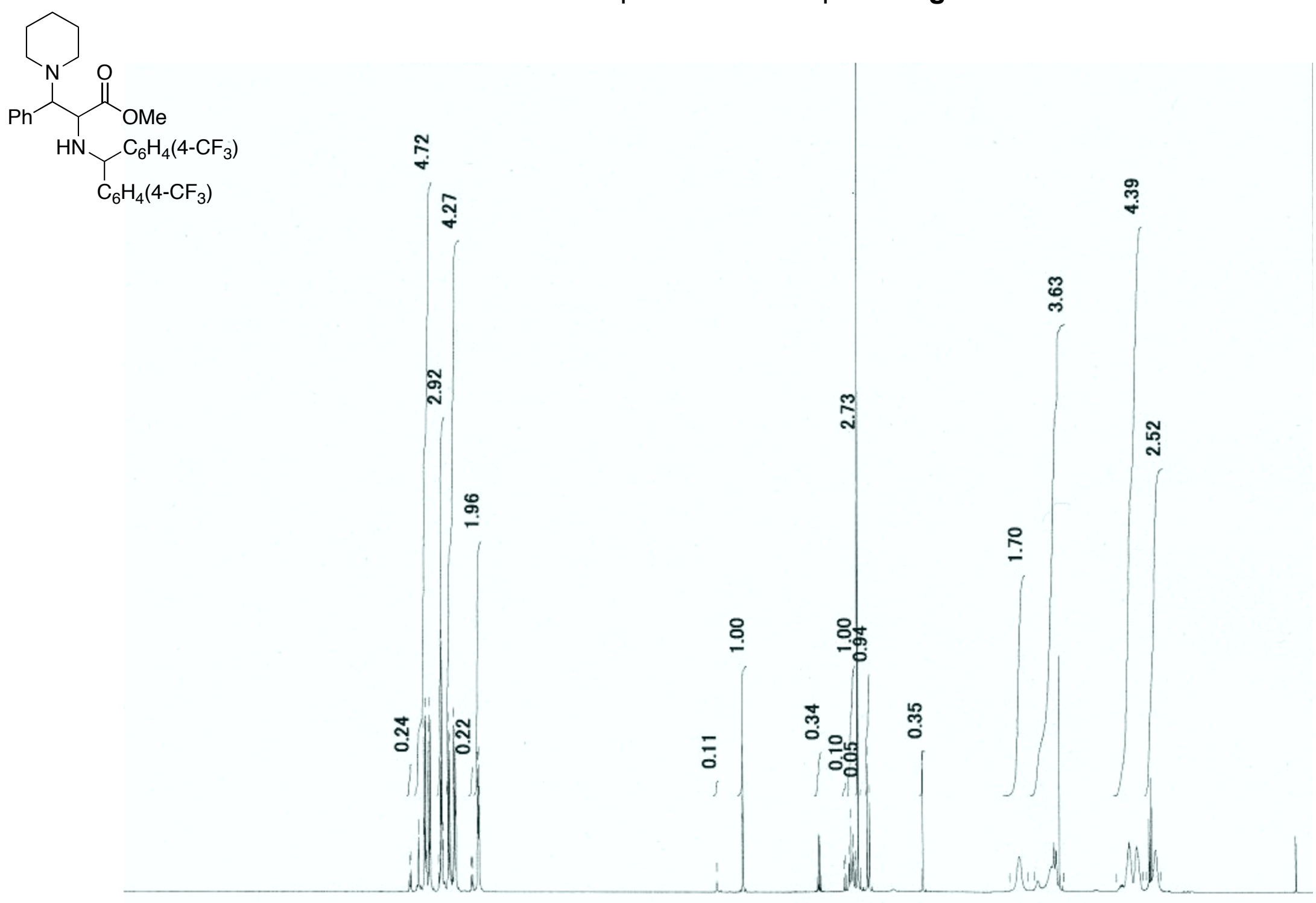

\%ู้
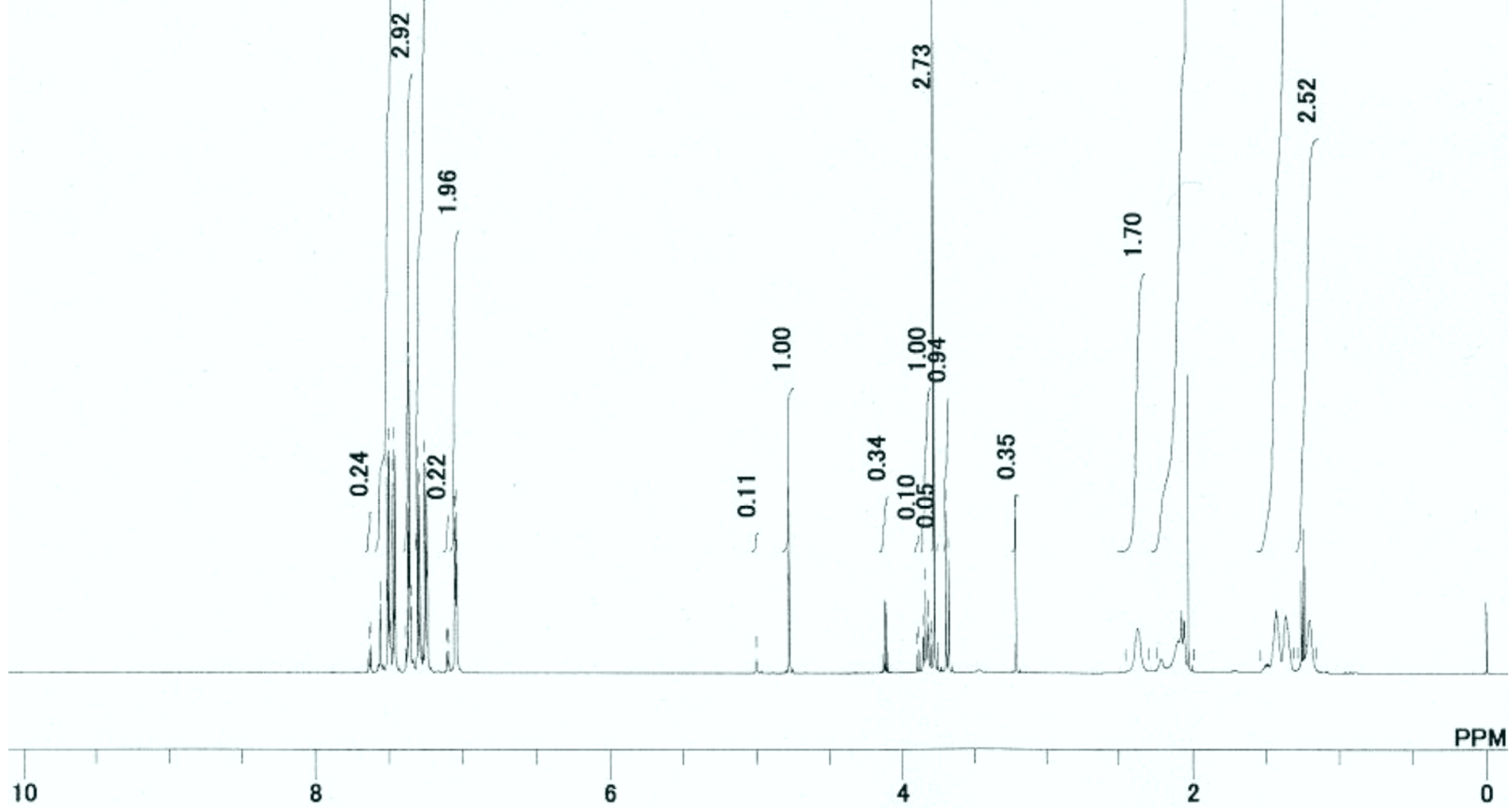

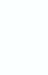
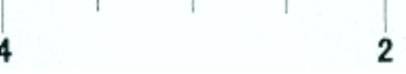

PPM 


\section{${ }^{13} \mathrm{C}$ NMR spectrum of compound $\mathbf{2} \mathbf{g}$}

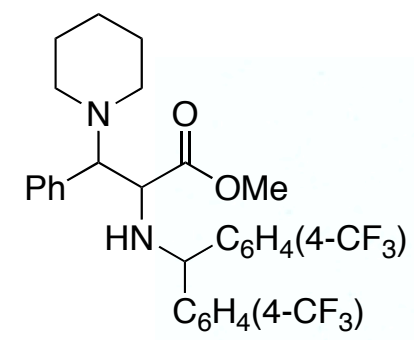




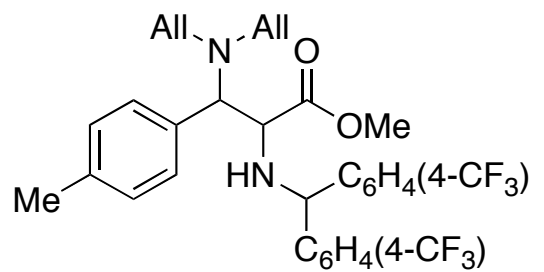

${ }^{1} \mathrm{H}$ NMR spectrum of compound $\mathbf{2 h}$

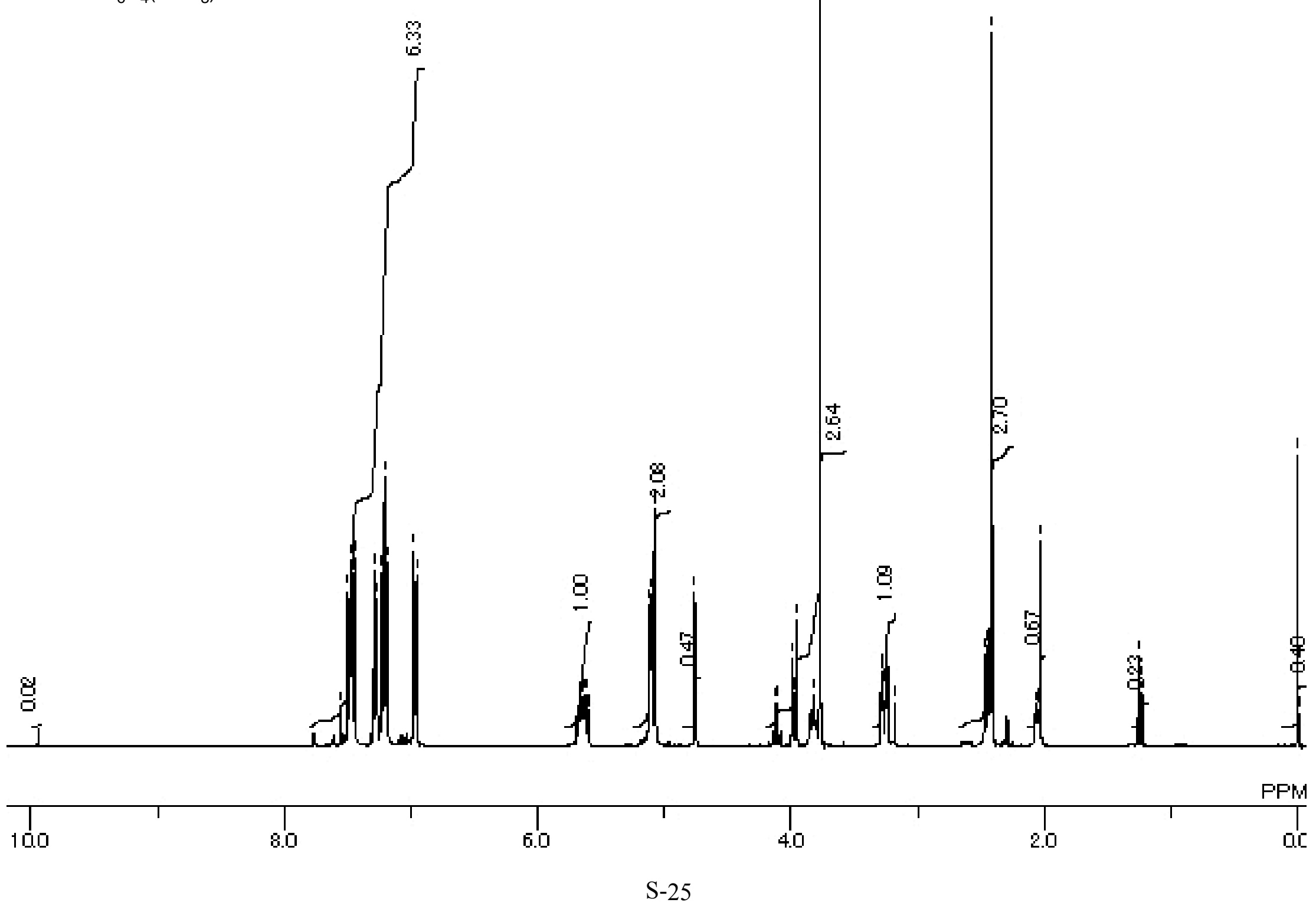




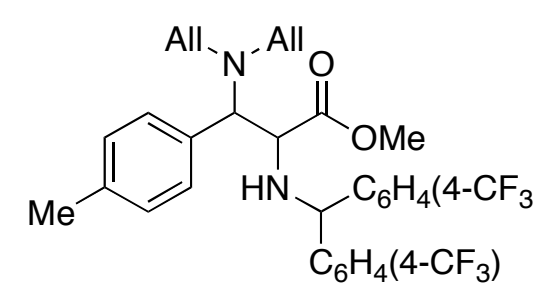

${ }^{13} \mathrm{C}$ NMR spectrum of compound $\mathbf{2 h}$

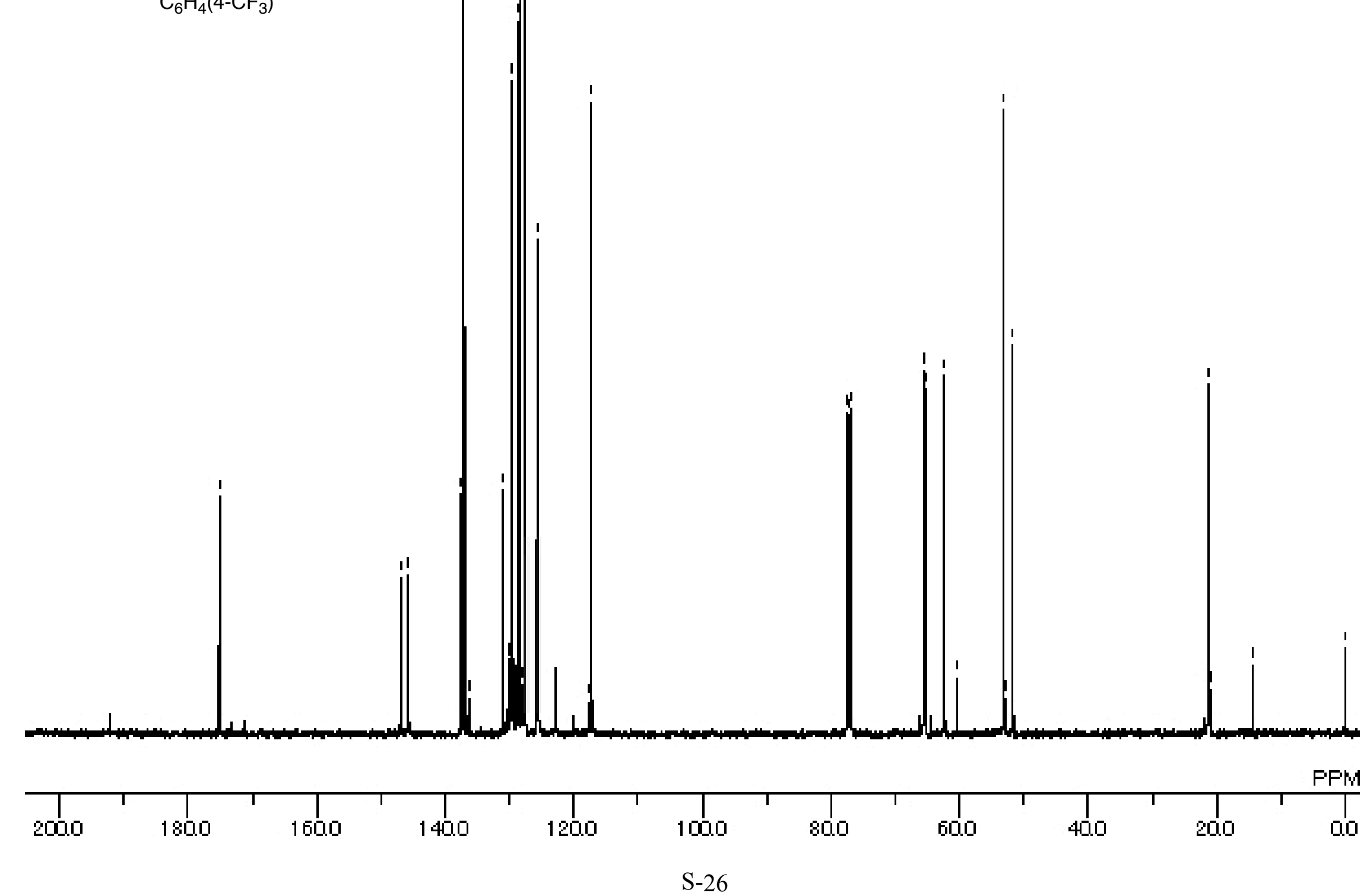




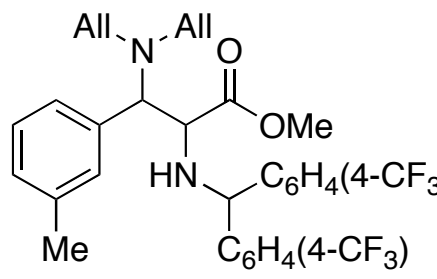

${ }^{1} \mathrm{H}$ spectrum of compound $\mathbf{2 i}$

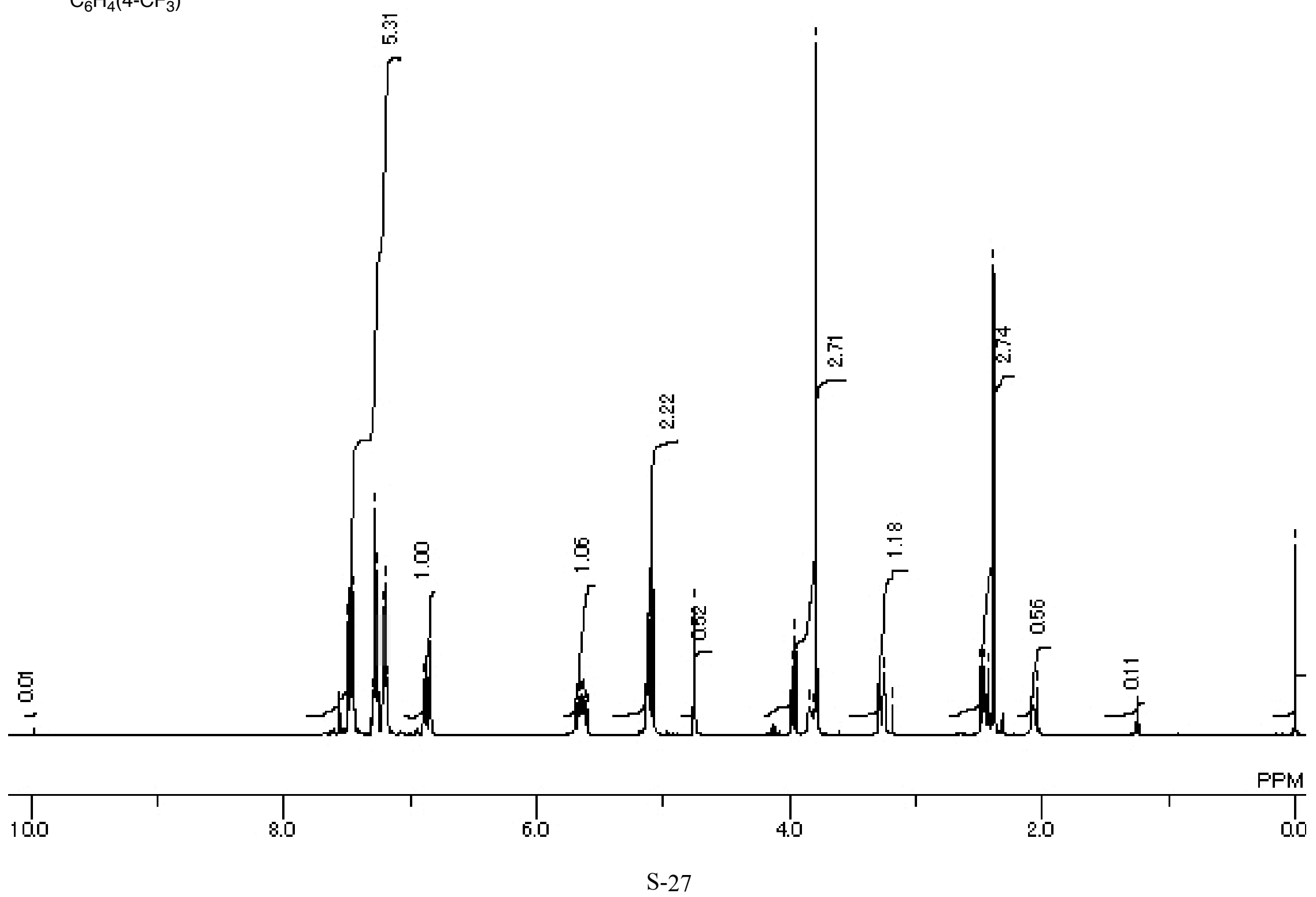


<smiles>COC(=O)C(NC(CCC(C)(F)F)CC(C)(F)F)C(c1cccc(C)c1)N([Al])[Al]</smiles>

${ }^{13} \mathrm{C}$ NMR spectrum of compound $\mathbf{2} \mathbf{i}$
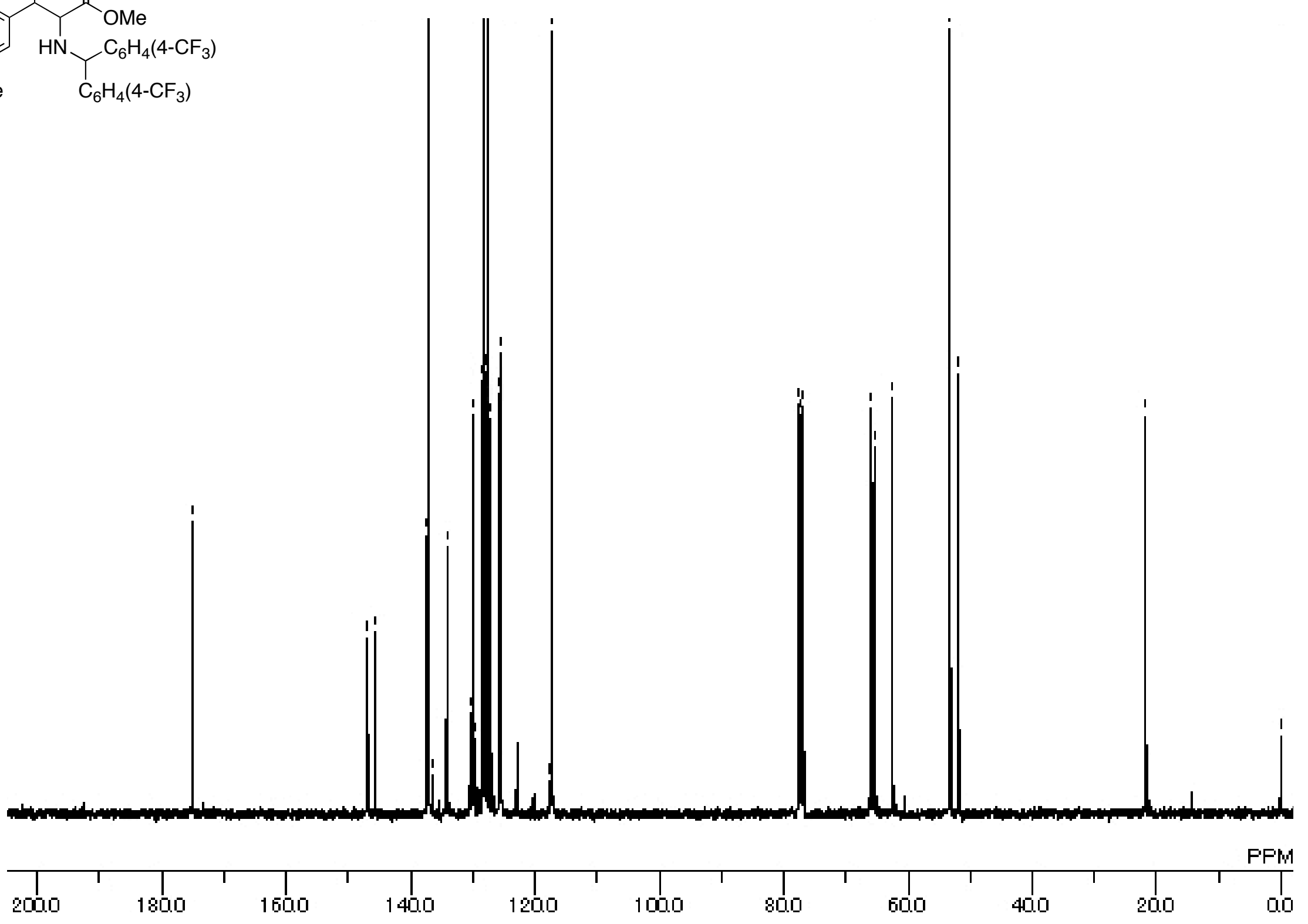

S-28 


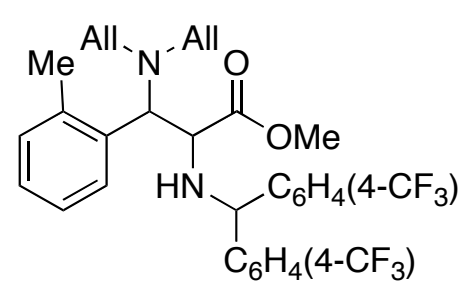

${ }^{1} \mathrm{H}$ NMR spectrum of compound $\mathbf{2 j}$

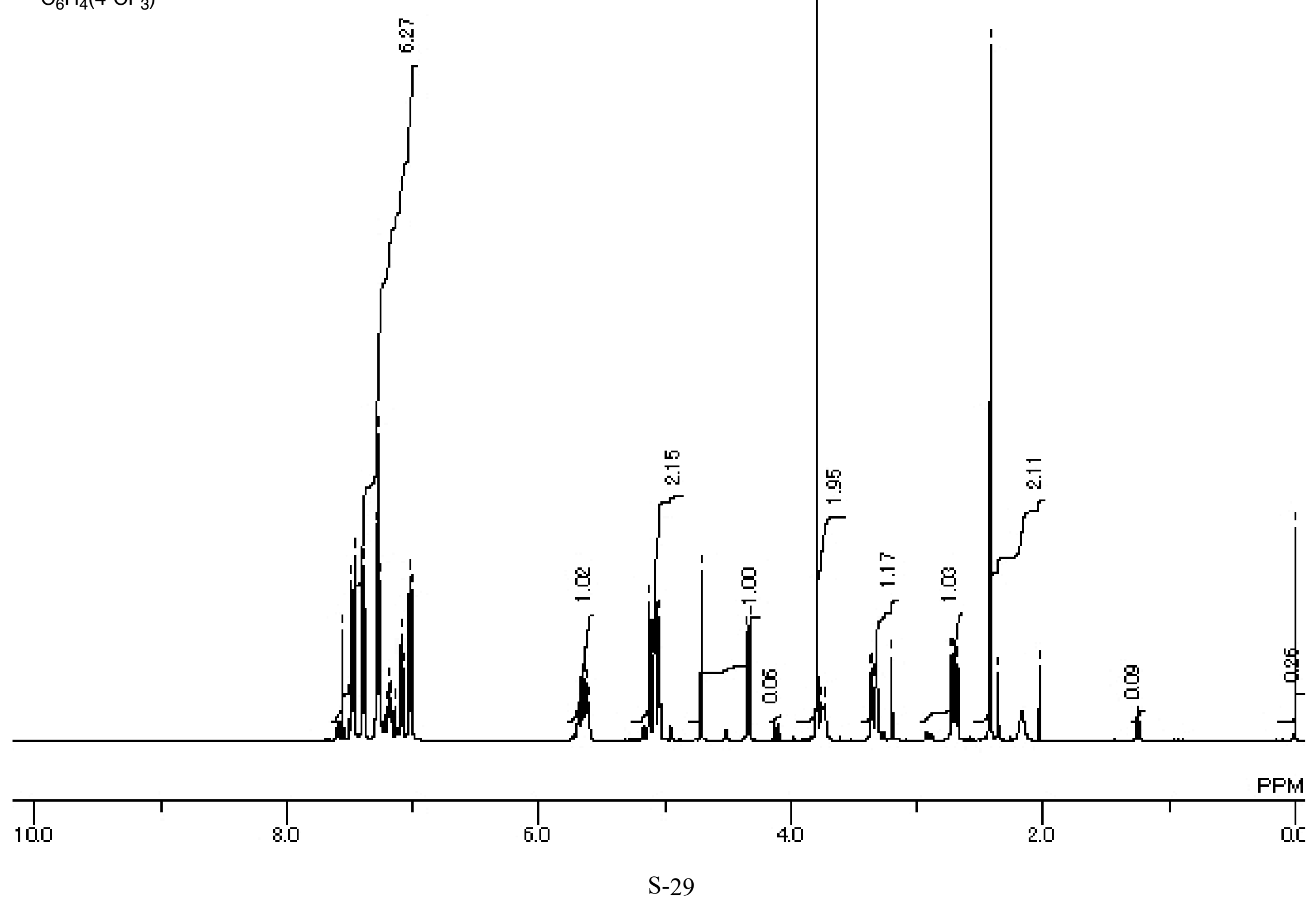


${ }^{13} \mathrm{C}$ NMR spectrum of compound $\mathbf{2} \mathbf{j}$
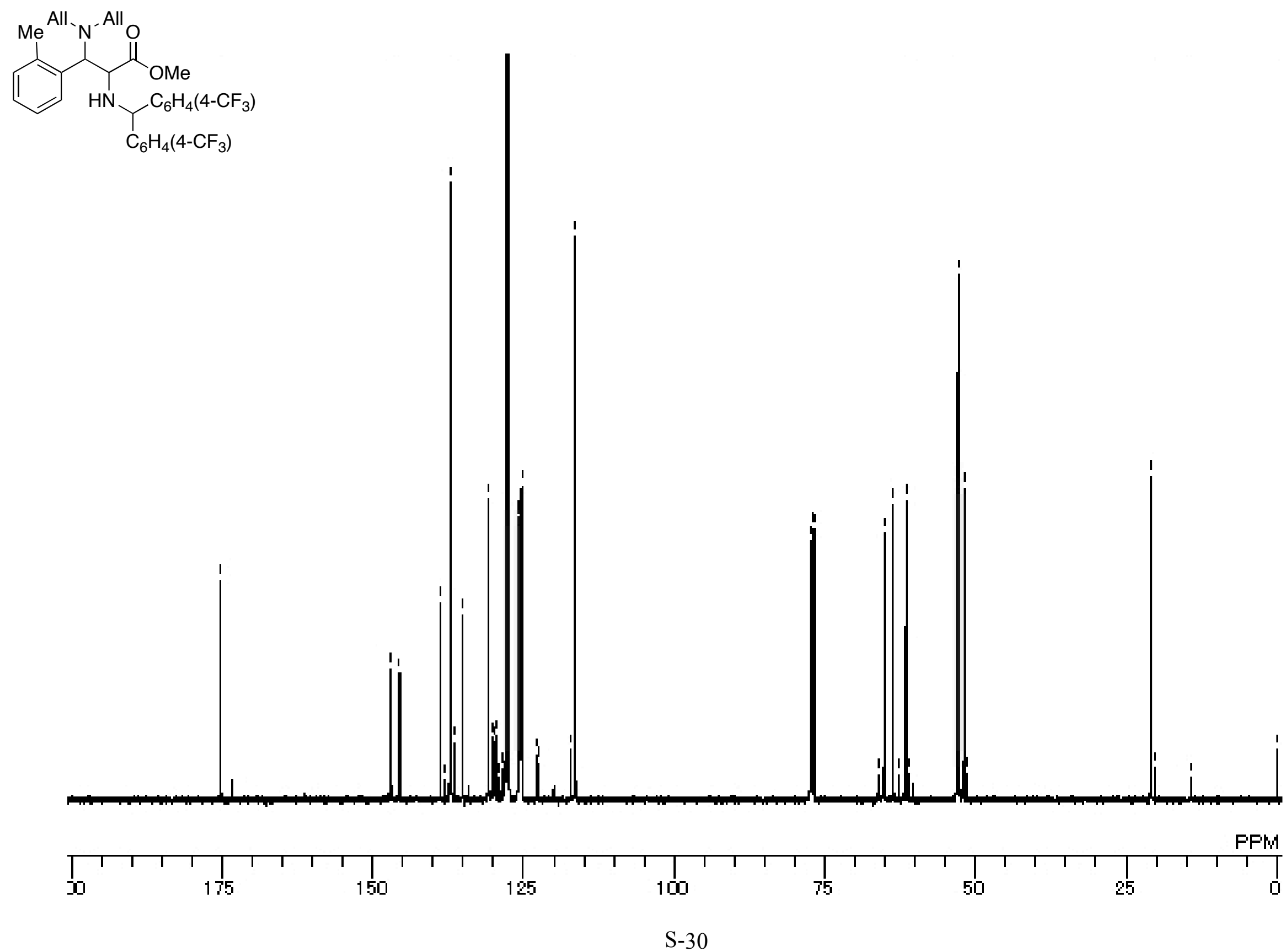


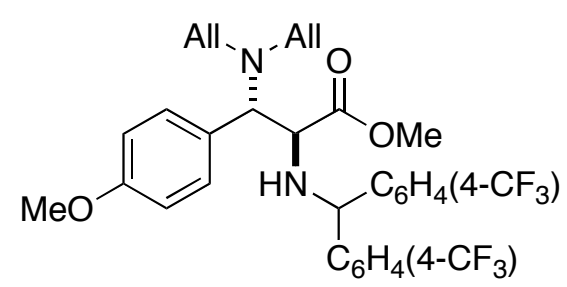

${ }^{1} \mathrm{H}$ NMR spectrum of compound $\mathbf{2 k}$

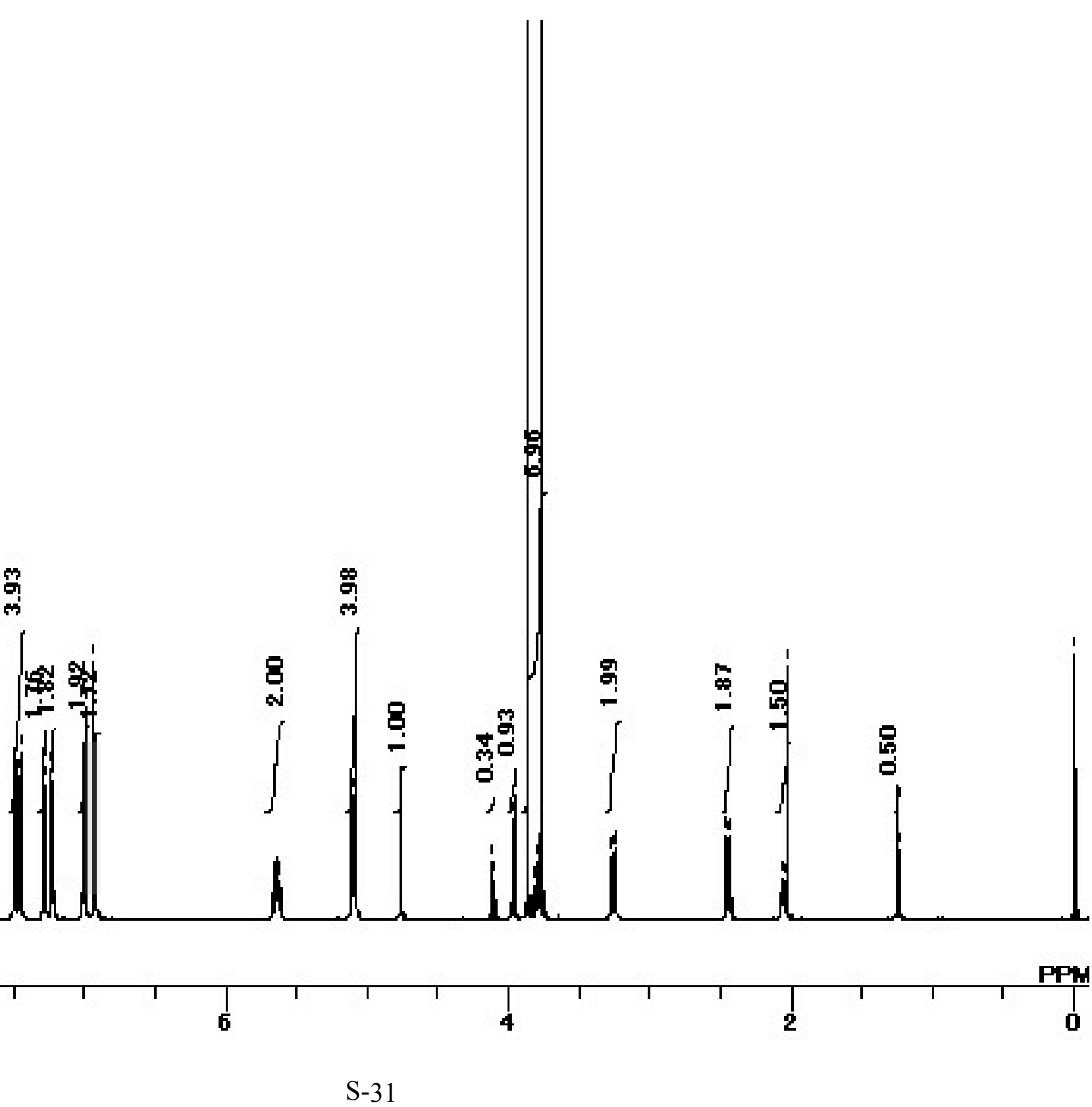


${ }^{13} \mathrm{C}$ NMR spectrum of compound $\mathbf{2 k}$
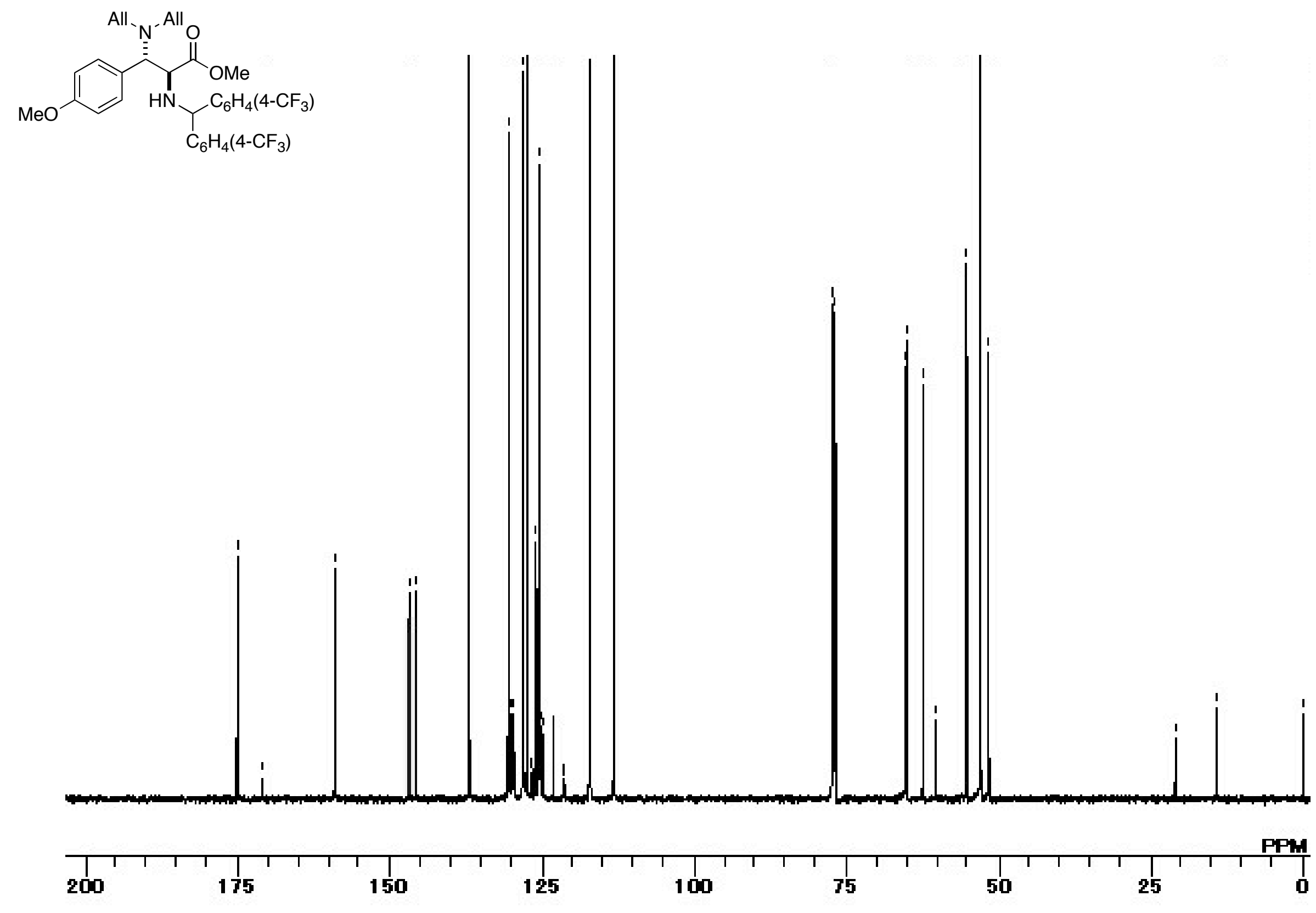


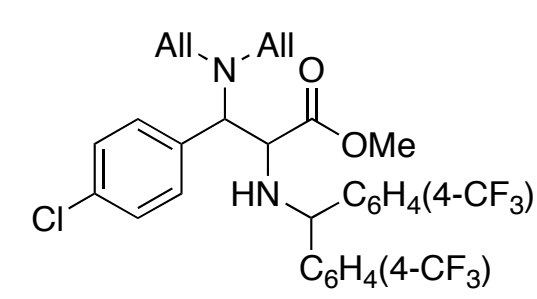

${ }^{1} \mathrm{H}$ NMR spectrum of compound $\mathbf{2 I}$

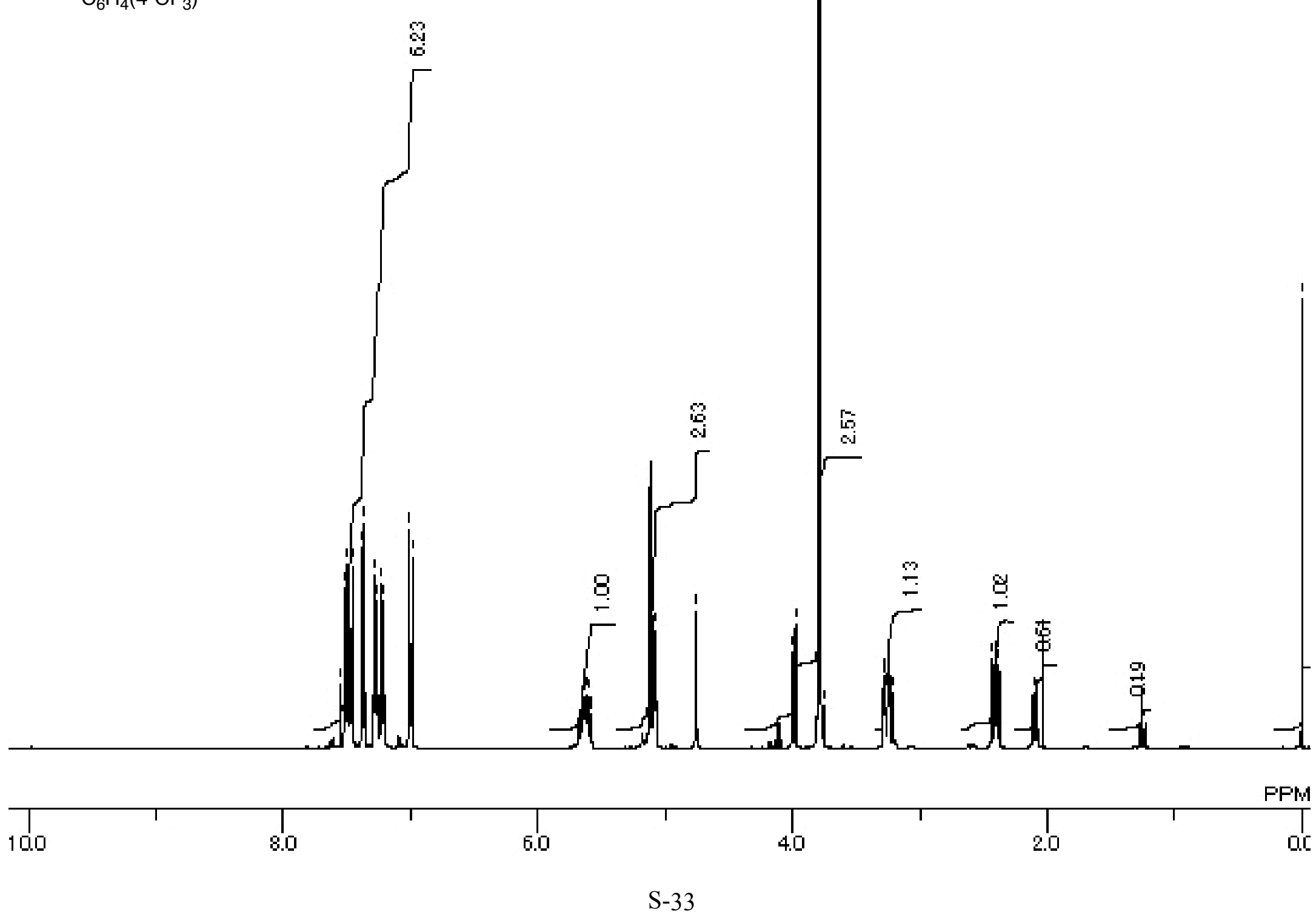


${ }^{13} \mathrm{C}$ NMR spectrum of compound 2 I
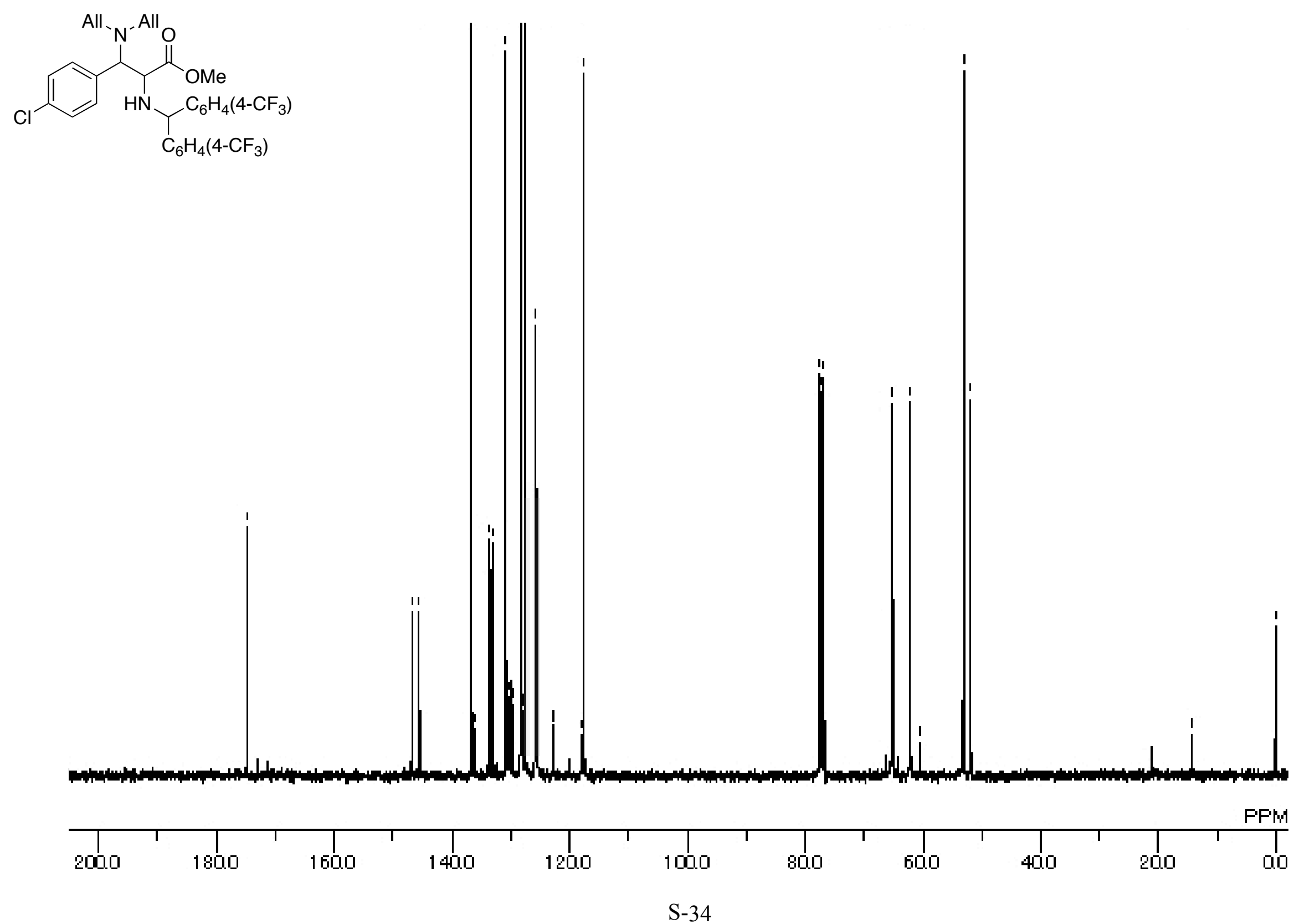


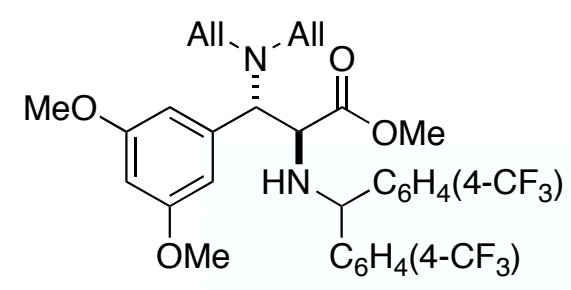

${ }^{1} \mathrm{H}$ NMR spectrum of compound $2 \mathrm{~m}$

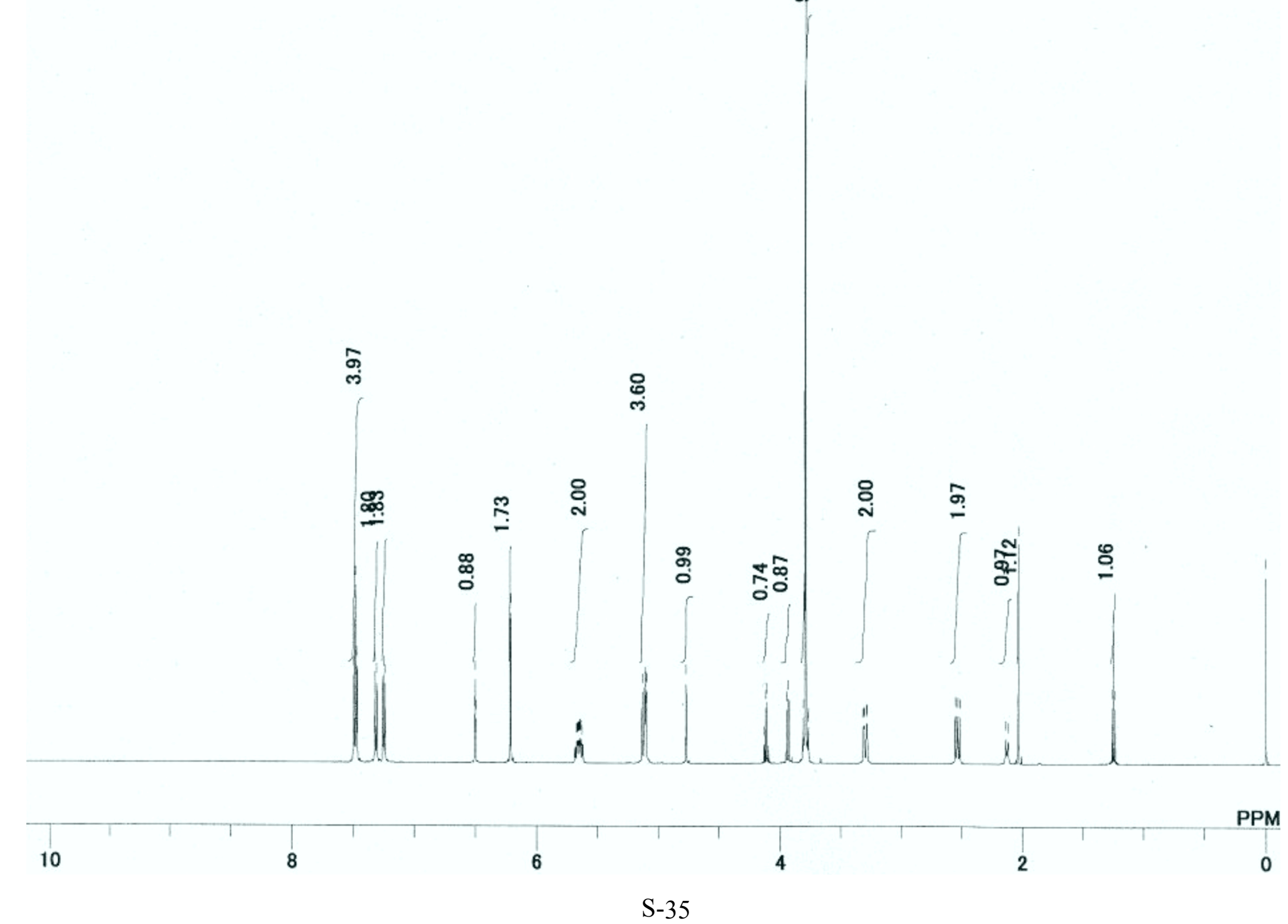


${ }^{13} \mathrm{C}$ NMR spectrum of compound $\mathbf{2 m}$
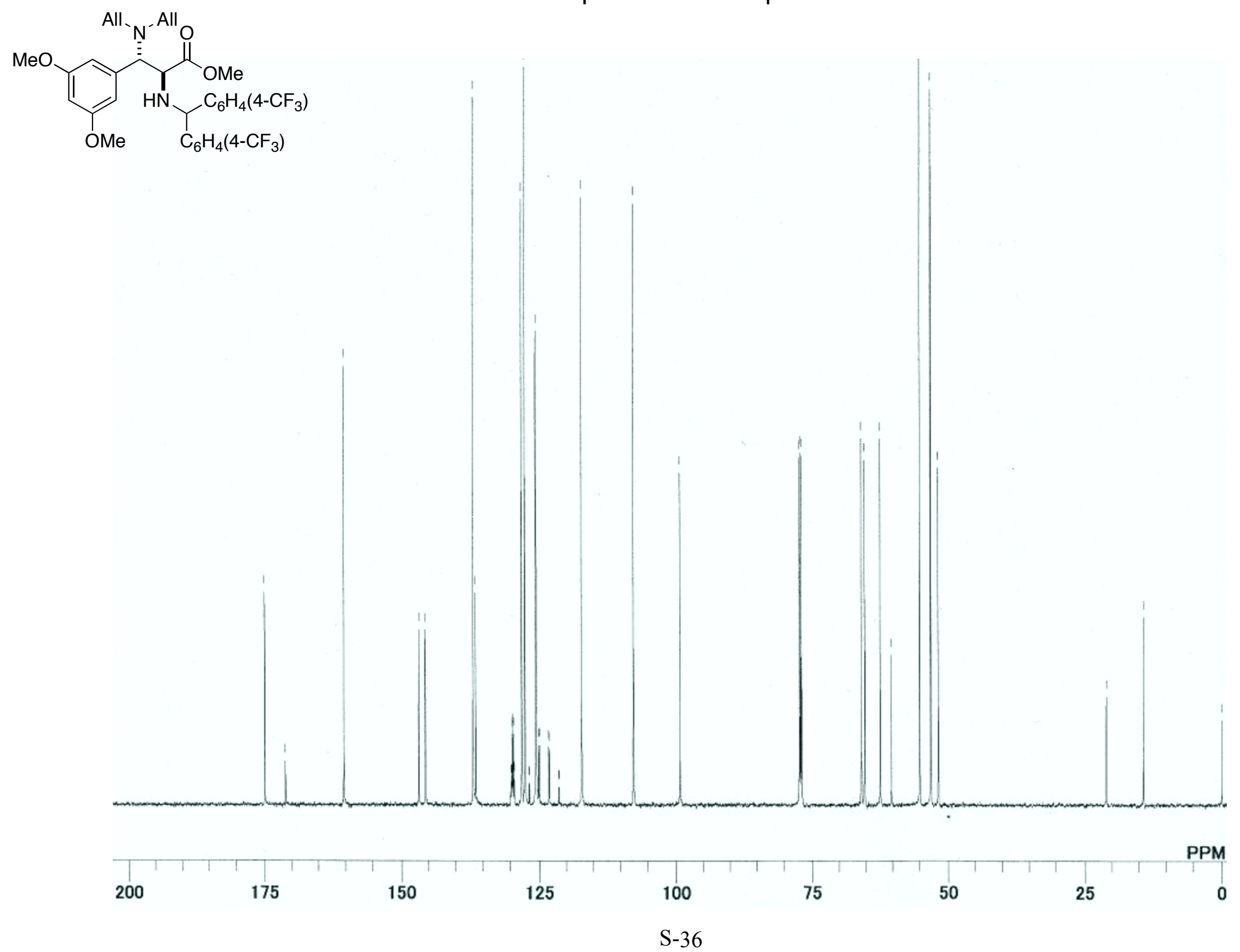


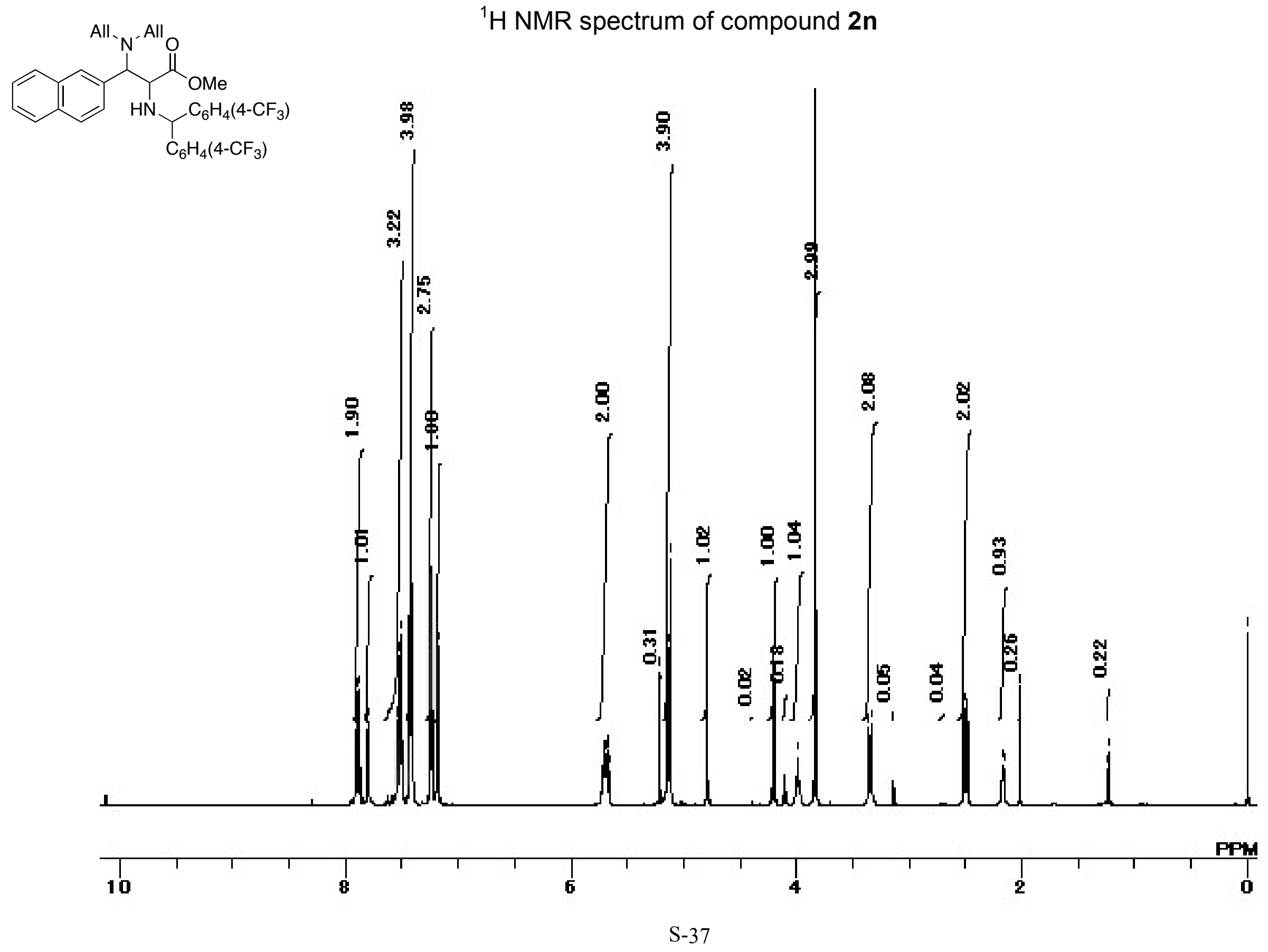


${ }^{13} \mathrm{C}$ NMR spectrum of compound $\mathbf{2 n}$
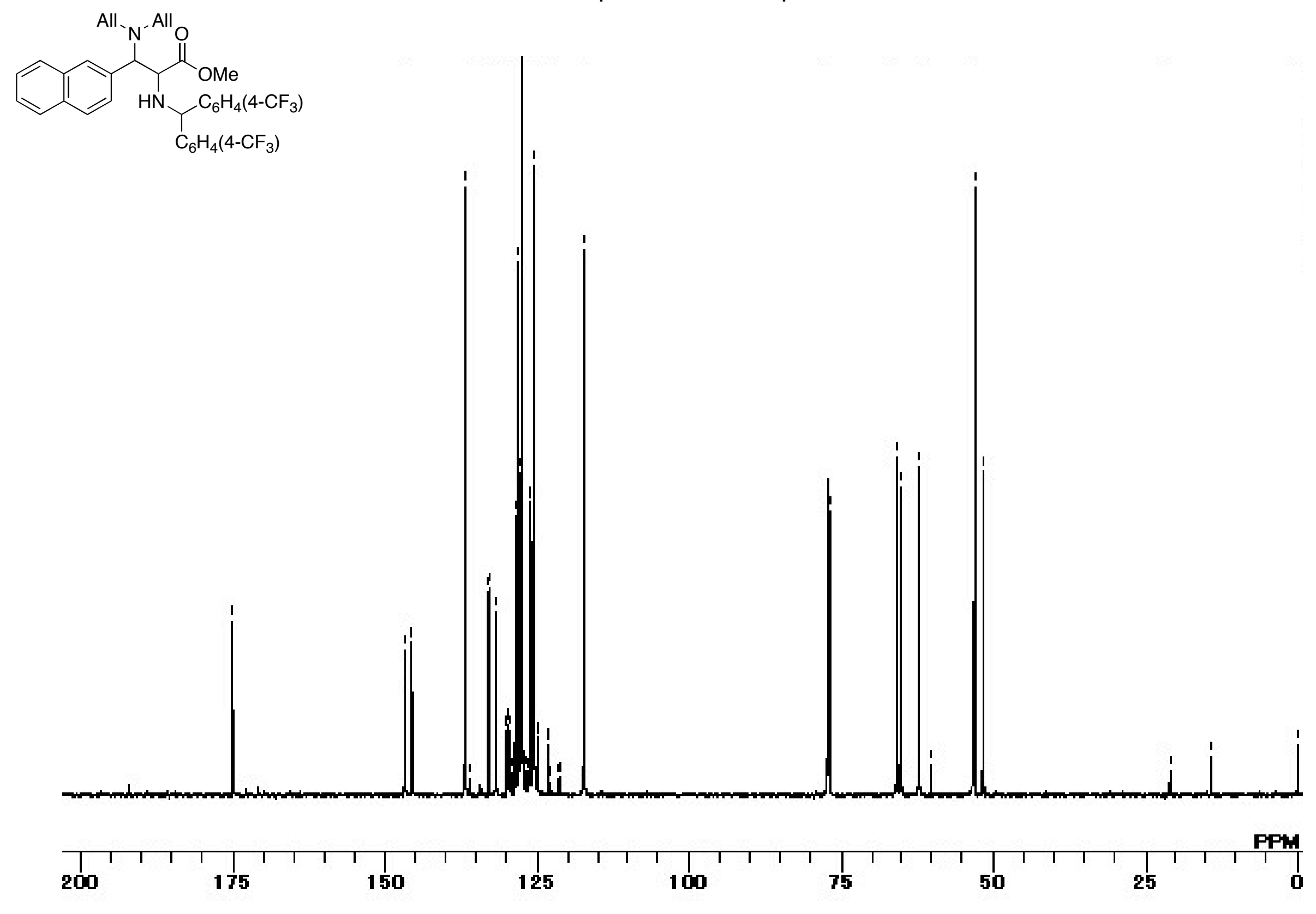


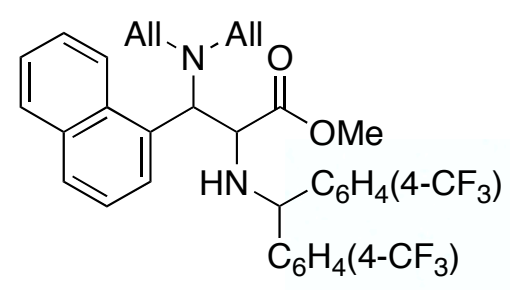

${ }^{1} \mathrm{H}$ NMR spectrum of compound $\mathbf{2 0}$

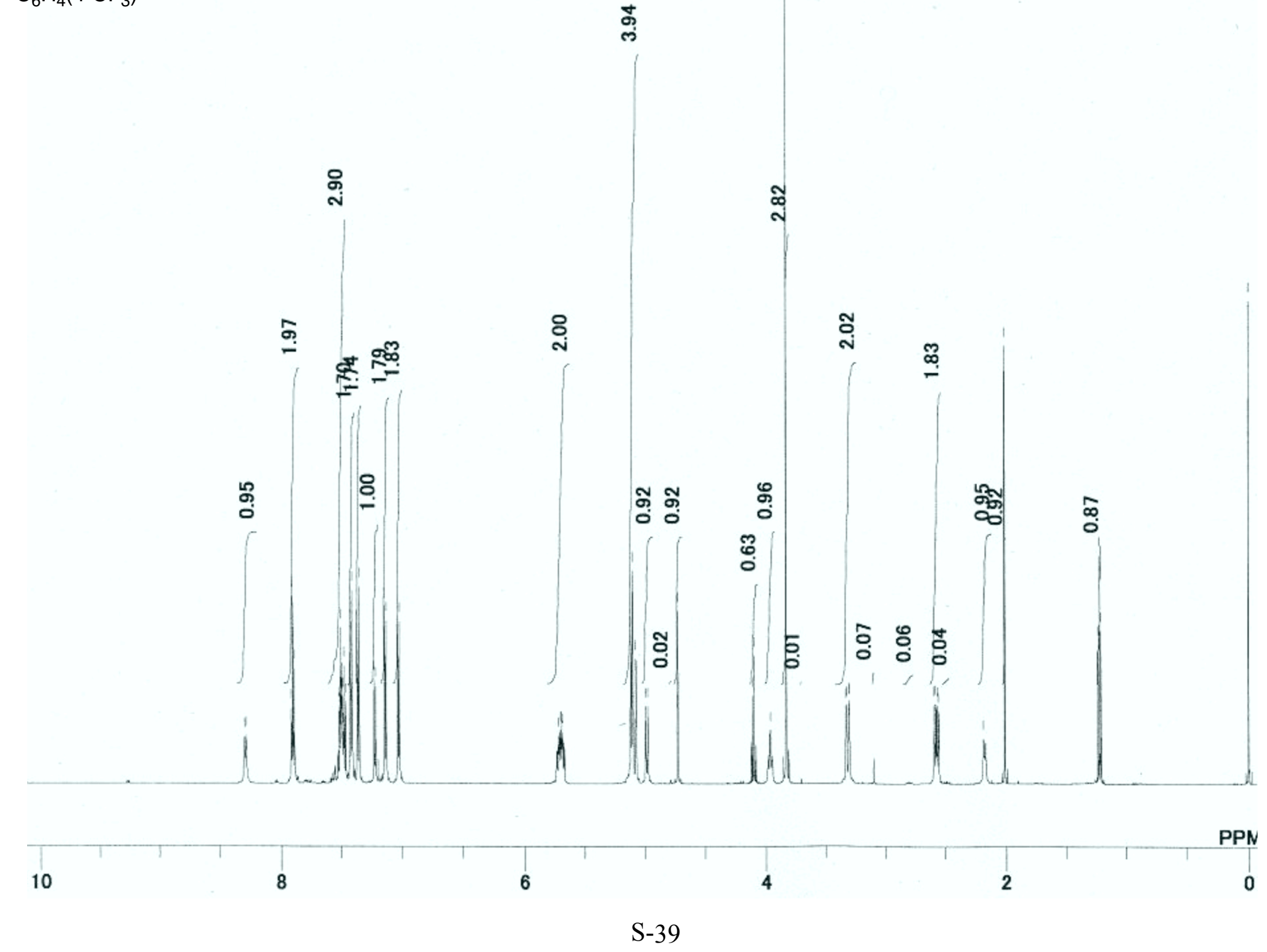




\section{${ }^{13} \mathrm{C}$ NMR spectrum of compound 20}
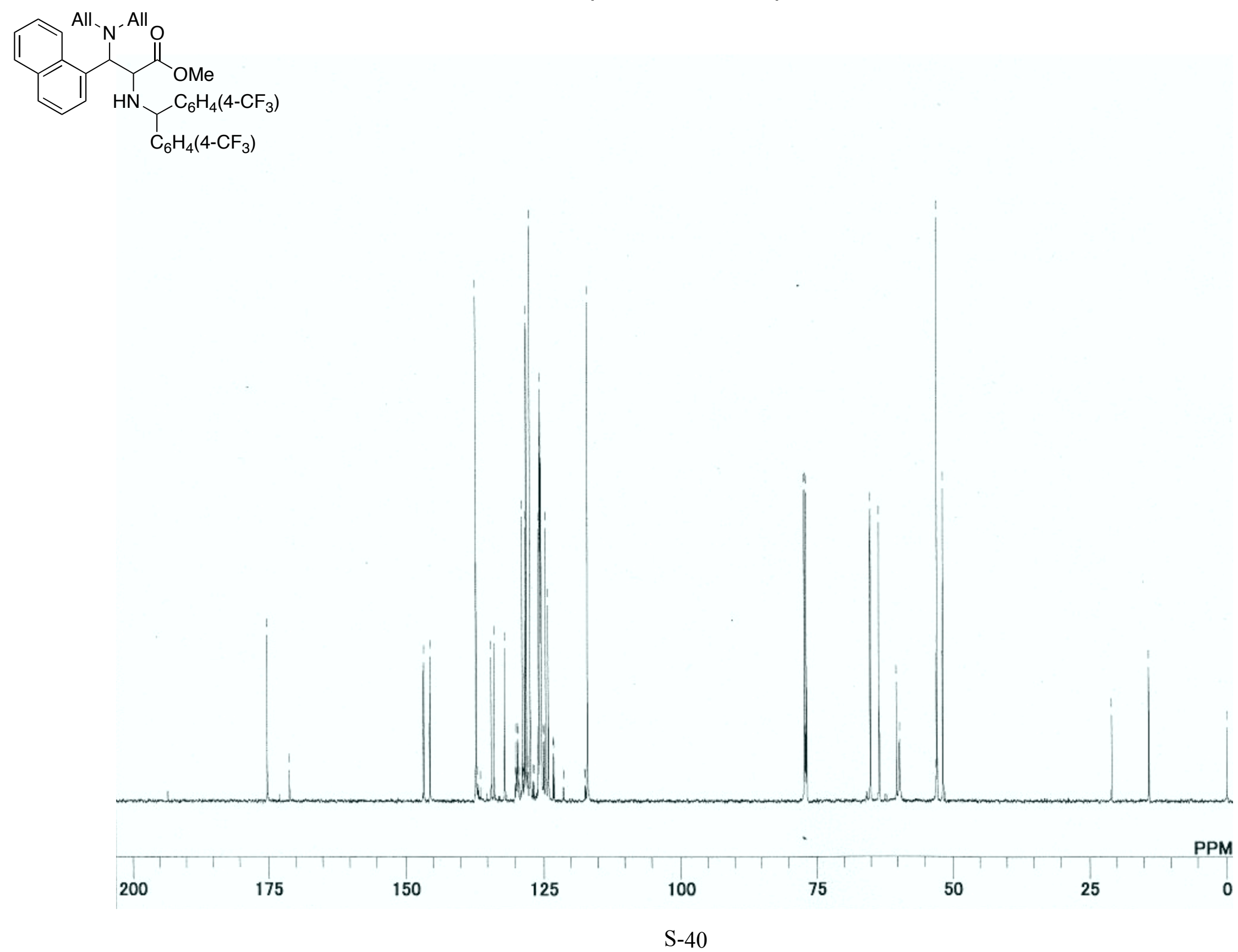


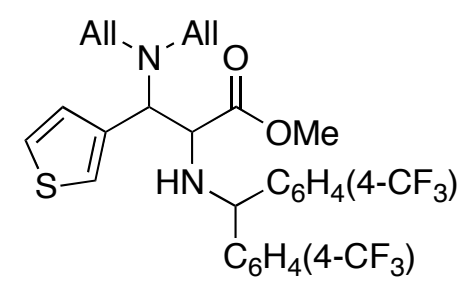

${ }^{1} \mathrm{H}$ NMR spectrum of compound $\mathbf{2 p}$

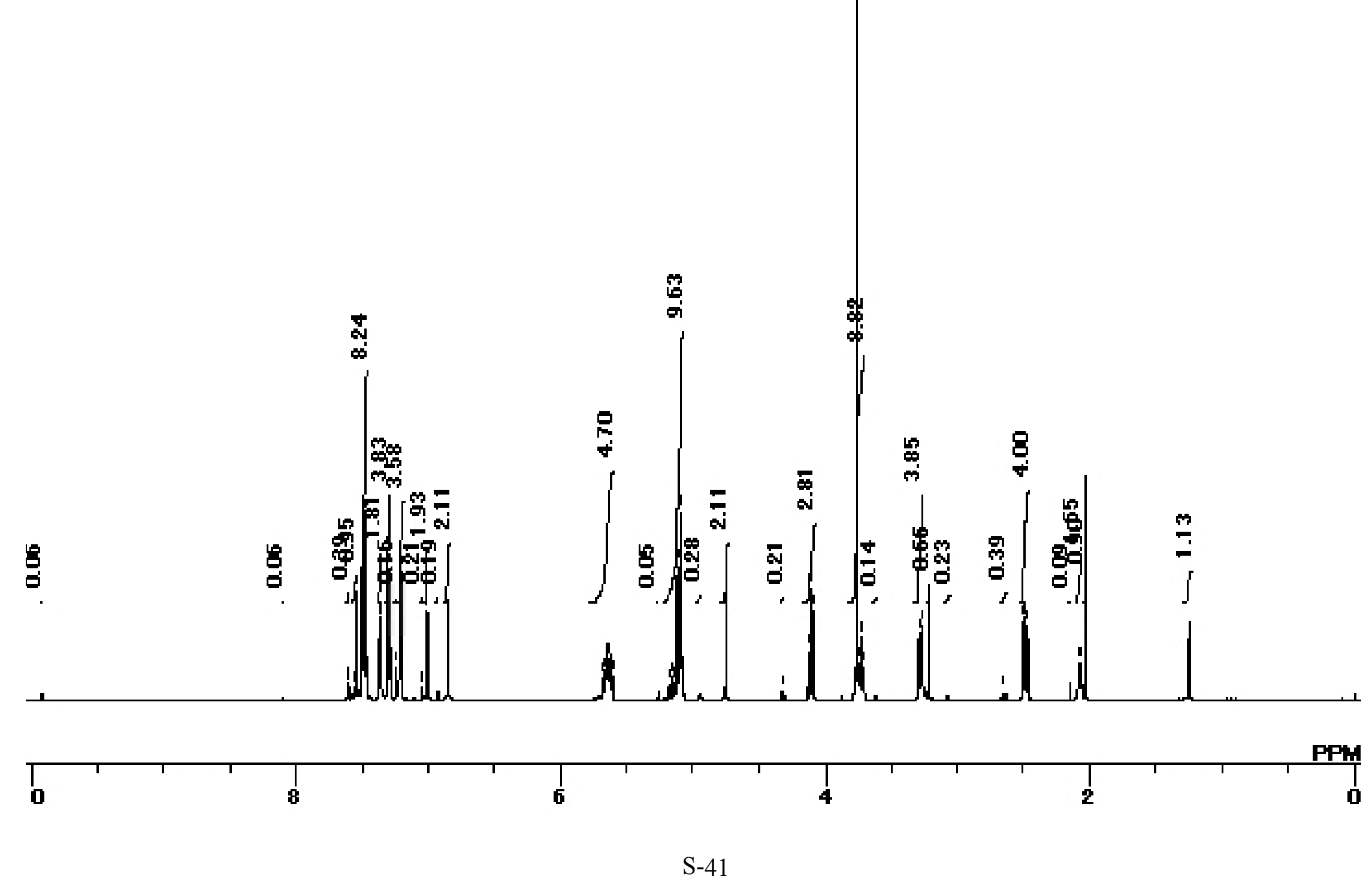




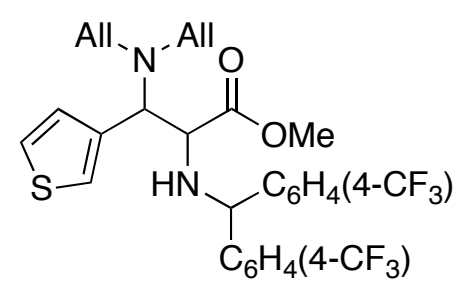

${ }^{13} \mathrm{C}$ NMR spectrum of compound $2 p$

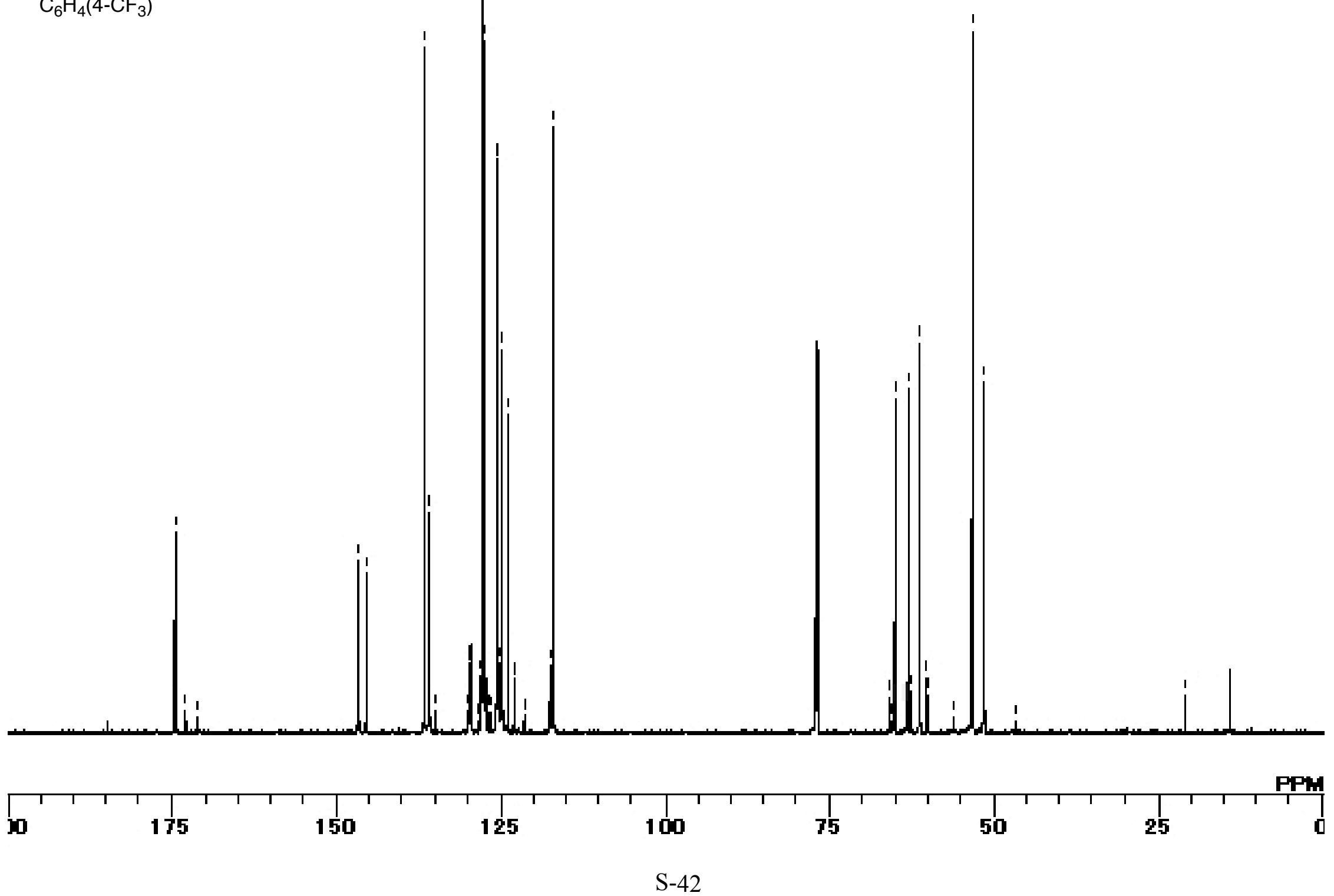




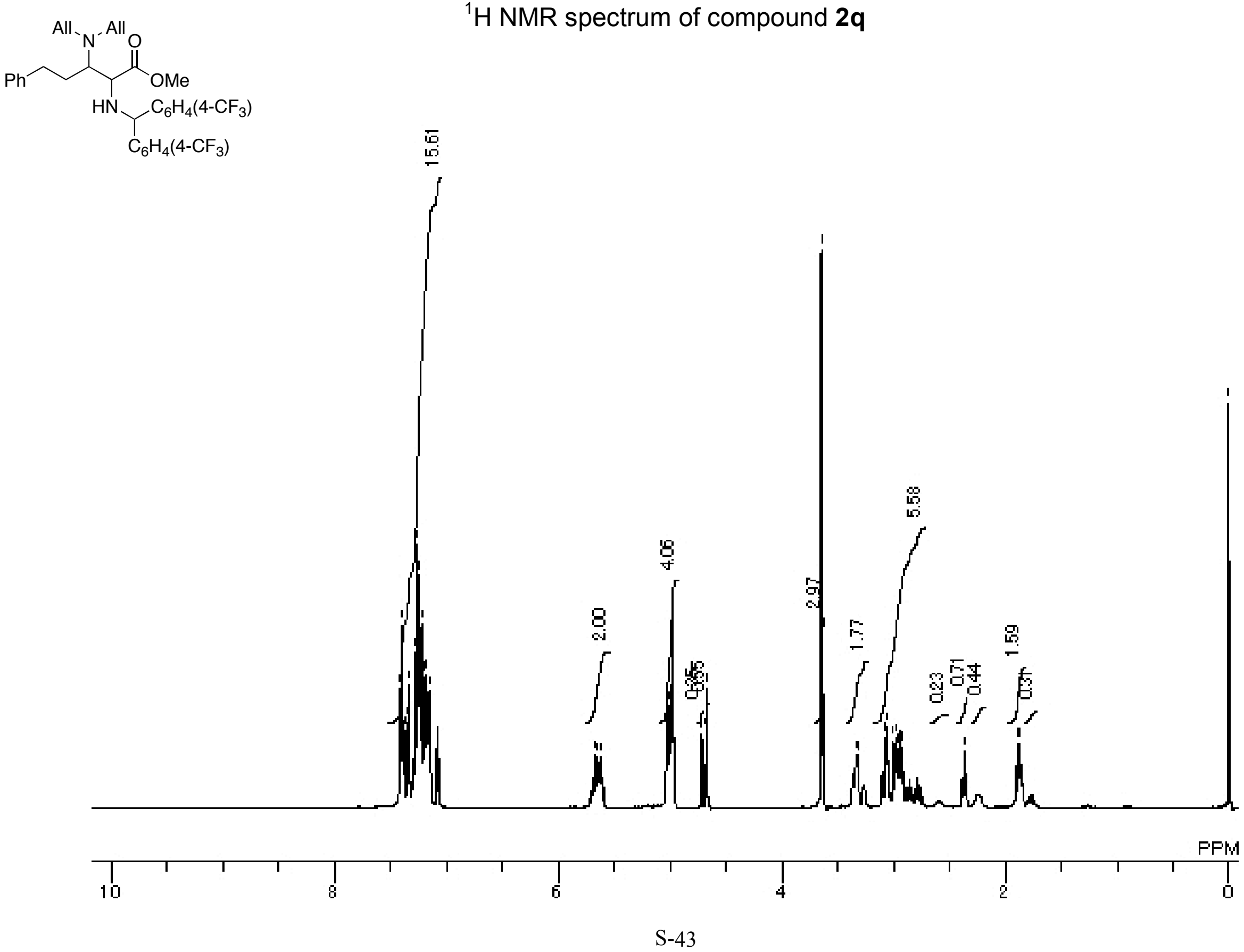


${ }^{13} \mathrm{C}$ NMR spectrum of compound $\mathbf{2 q}$
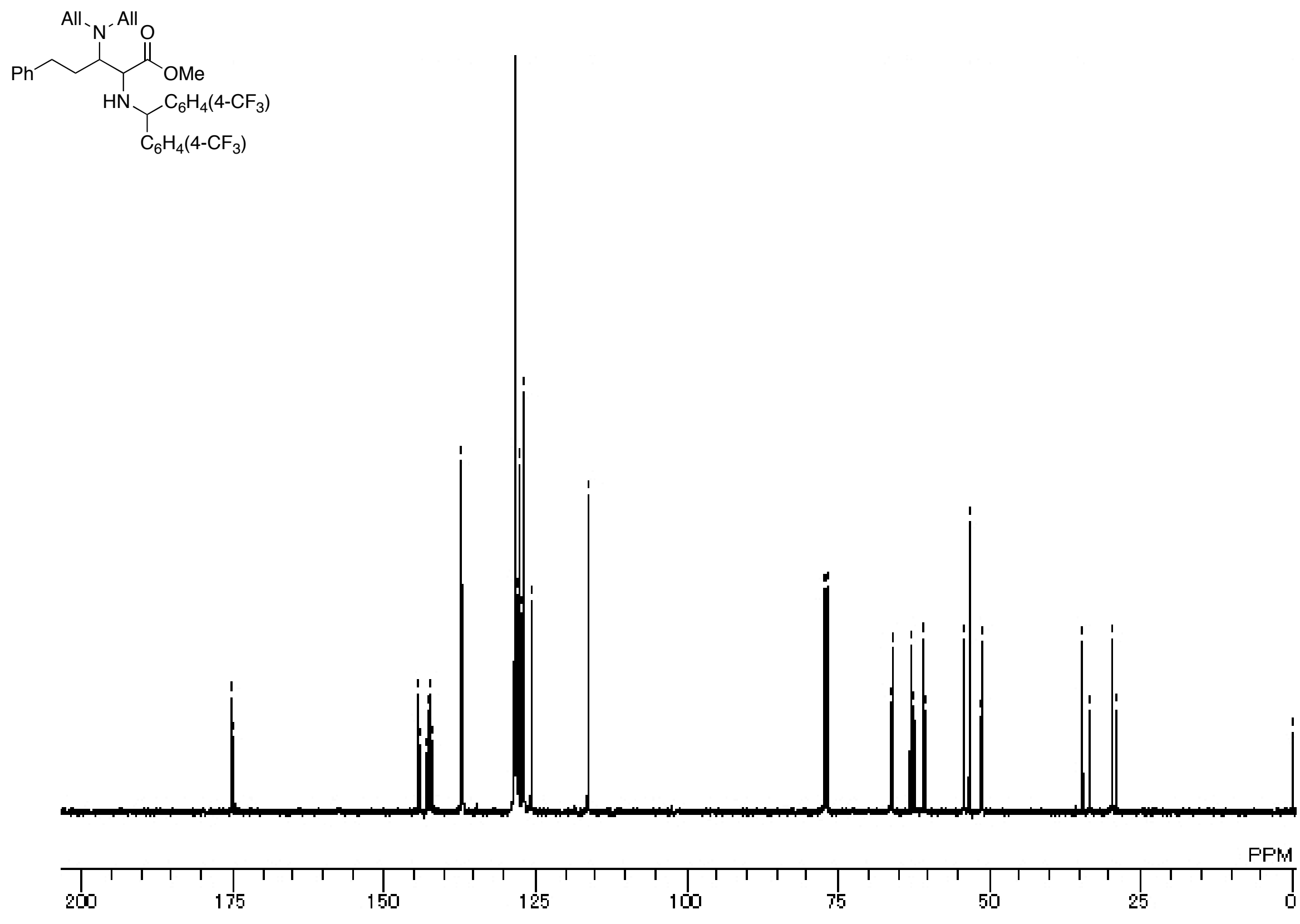

S-44 
${ }^{1} \mathrm{H}$ NMR spectrum of compound $\mathbf{5}$
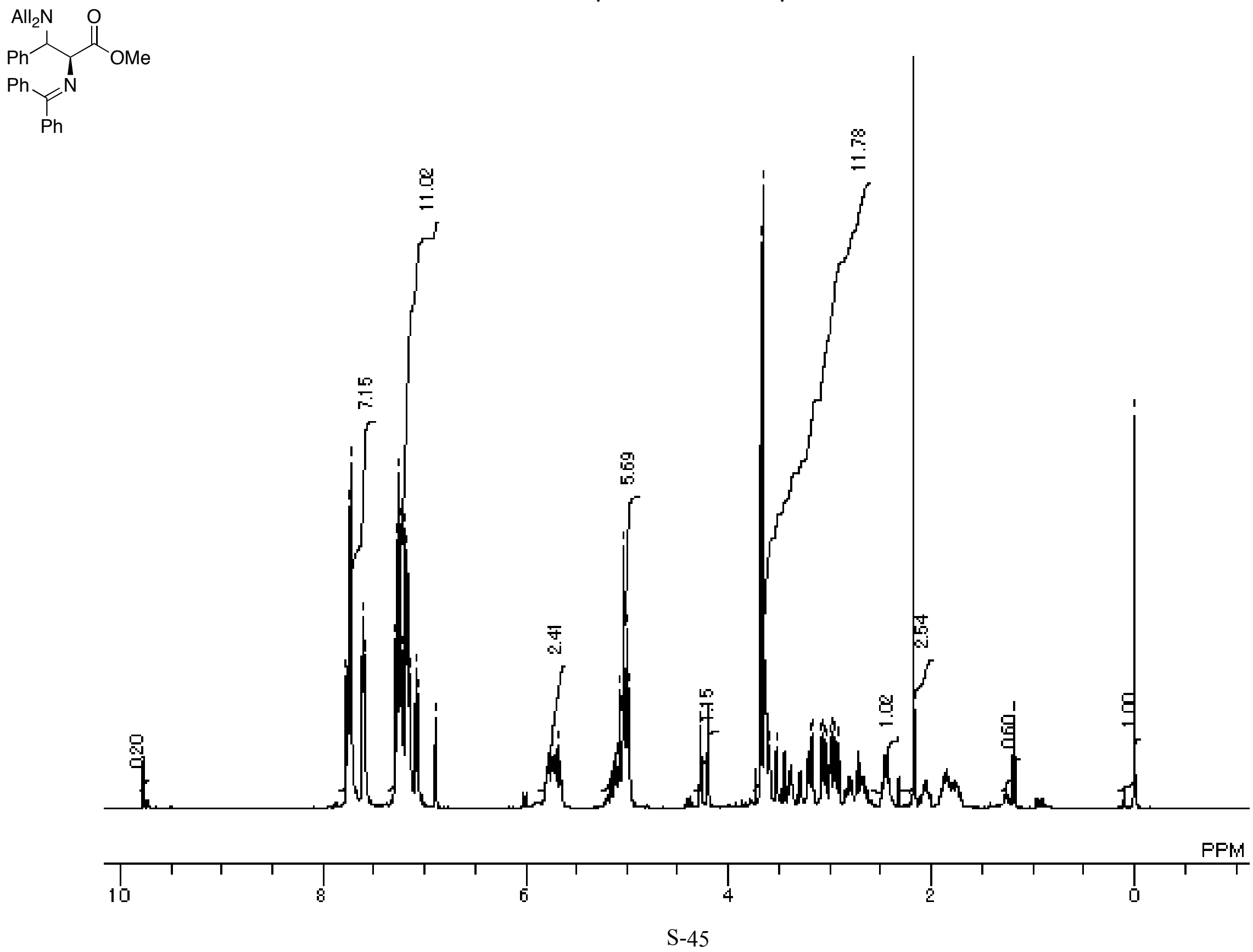